\title{
Engineering the flagellar type III secretion system: improving capacity for secretion of recombinant protein
}

\author{
Charlotte A. Green ${ }^{1,5}$, Nitin S. Kamble', Elizabeth K. Court ${ }^{1}$, Owain J. Bryant ${ }^{3}$, Matthew G. Hicks ${ }^{1}$, \\ Christopher Lennon ${ }^{4}$, Gillian M. Fraser ${ }^{3}$, Phillip C. Wright ${ }^{2}$ and Graham P. Stafford ${ }^{1 *}$ (D)
}

\begin{abstract}
Background: Many valuable biopharmaceutical and biotechnological proteins have been produced in Escherichia coli, however these proteins are almost exclusively localised in the cytoplasm or periplasm. This presents challenges for purification, i.e. the removal of contaminating cellular constituents. One solution is secretion directly into the surrounding media, which we achieved via the 'hijack' of the flagellar type III secretion system (FT3SS). Ordinarily flagellar subunits are exported through the centre of the growing flagellum, before assembly at the tip. However, we exploit the fact that in the absence of certain flagellar components (e.g. cap proteins), monomeric flagellar proteins are secreted into the supernatant.
\end{abstract}

Results: We report the creation and iterative improvement of an E. coli strain, by means of a modified FT3SS and a modular plasmid system, for secretion of exemplar proteins. We show that removal of the flagellin and HAP proteins (FliC and FlgKL) resulted in an optimal prototype. We next developed a high-throughput enzymatic secretion assay based on cutinase. This indicated that removal of the flagellar motor proteins, motAB (to reduce metabolic burden) and protein degradation machinery, ClpX (to boost FT3SS levels intracellularly), result in high capacity secretion. We also show that a secretion construct comprising the $5^{\prime} U T R$ and first 47 amino acidsof FliC from E. coli (but no 3'UTR) achieved the highest levels of secretion. Upon combination, we show a 24-fold improvement in secretion of a heterologous (cutinase) enzyme over the original strain. This improved strain could export a range of pharmaceutically relevant heterologous proteins $\left[\mathrm{hGH}, \operatorname{Tr} x \mathrm{~A}, \mathrm{ScFv}\left(\mathrm{CH}_{2}\right)\right]$, achieving secreted yields of up to $0.29 \mathrm{mg} \mathrm{L}^{-1}$, in low cell density culture.

Conclusions: We have engineered an E. coli which secretes a range of recombinant proteins, through the FT3SS, to the extracellular media. With further developments, including cell culture process strategies, we envision further improvement to the secreted titre of recombinant protein, with the potential application for protein production for biotechnological purposes.

Keywords: Recombinant protein secretion, Flagellar, Strain engineering, Secretion assay, Biotechnology, Synthetic biology

\footnotetext{
*Correspondence: g.stafford@sheffield.ac.uk

${ }^{1}$ Integrated BioSciences, School of Clinical Dentistry, University

of Sheffield, Sheffield S10 2TA, UK

Full list of author information is available at the end of the article
} 


\section{Background}

A persistent goal of biotechnology is to produce recombinant protein at reduced cost, while maintaining high product quality and yield. For many protein biologics, production in prokaryotes (chiefly in E. coli) is favoured. Major advantages include fast growth to high cell densities on cheap carbon sources, and simple scale up $[1,2]$. However, as in many industrial biotechnology (IB) processes, downstream processing accounts for a high proportion of costs [3-5]. If protein product was secreted by the expression organism into the growth media, these costs could be reduced, as purification could be simplified, i.e. eliminating the need to lyse cells, or to remove cellular contaminants, which can compromise product purity, and may elicit an immune response in humans (e.g. lipopolysaccharide in $E$. coli) [6-8]. In addition, product yield and quality may be increased, as secretion would bypass cytoplasmic and periplasmic proteases. Extracellular secretion may also improve protein folding and solubility, while also reducing the formation of inclusion bodies, thus increasing product yield and quality [9-12].

Secretion of heterologous protein in E. coli has been utilised, however the majority of work concerns secretion into the periplasm via Sec or Tat-dependent systems [10]. While this strategy can yield titres in the $\mathrm{mg} \mathrm{L}^{-1}$ range (e.g. $30 \mathrm{mg} \mathrm{L}^{-1}$ human growth hormone [13], $60 \mathrm{mg} \mathrm{L}^{-1}$ GFP [14]), this is only achieved following purification from the periplasm. Alternatively extracellular localisation of protein can be achieved In E. coli without directed secretion to the extracellular space via strategies that make use of 'leaky strains' [15], where heterologous proteins are fused to a secretion tag (for example ompA, ompC, pelB $[16,17]$ ), to enable directed secretion to the periplasm, followed by leaking into the supernatant. While titres may be favourable, the presence of additional periplasmic proteins adds complexity to purification, e.g. while $550 \mathrm{mg} \mathrm{L}^{-1}$ cell culture of lipase B tagged with the pelB signal sequence was found in the extracellular fraction of $E$. coli, high concentrations of periplasmic proteins were also detected, and only one-fifth of the product was able to be recovered [18]. To date, true secretion (i.e. to the extracellular space via a defined secretion system, rather than through leaking or lysis) of heterologous protein by prokaryotes has been achieved at up to approximately $50 \mathrm{mg} \mathrm{L}^{-1}$, in organisms such as Bacillus and Pseudomonas [19-21], as opposed to the $\mathrm{g} \mathrm{L}^{-1}$ titres achieved in eukaryotes such as Pichia pastoris [22]. In E. coli, attempts to secrete proteins directly into the media have been limited, with evidence of low levels (i.e. $1 \mu \mathrm{g}$ to $1 \mathrm{mg} \mathrm{L}^{-1}$ of heterologous protein) via type I secretion system (T1SS) using either the Haemolysin or lipase transporting $\mathrm{ABC}$ transporter systems [23-28]. Another option for direct secretion into the media, is the bacterial flagellar type III secretion system, which has been utilised in E. coli [29-32], Bacillus [20] and Salmonella enterica sv. Typhimurium [33-36]. In addition, secretion of up to $30 \mathrm{mg} \mathrm{L}^{-1}$ of a range of polymers [37], such as tropo-elastin and spider silk, have also been reported using the injectisome type III secretion system of $S$. enterica [37-39].

In this report we focus on the E. coli FT3SS, due to a preference in IB for both $E$. coli, and non-pathogenicity associated secretion systems. E. coli have 4-10 flagellum of around $20 \mu \mathrm{m}$ in length, each comprising of up to 30,000 flagellin (FliC) monomers [40-43]. The FT3SS, despite having evolved to build a flagellum and provide motility to the cell, is effectively an efficient protein secretion machineable to assemble a multi-component structure composed of several thousand subunits on its surface. Proteins initially assemble at the inner membrane, resulting in a pore of about $2.0 \mathrm{~nm}$ diameter, through which the majority of the remaining flagellar proteins are exported, unfolded, to the distal end of the existing flagellar structure [44]. Therefore in the context of biotechnology, the FT3SS may provide a one step, high capacity route for protein export.

The basic flagellar structure is comprised of the basal body (motor and secretion apparatus), hook (universal joint), and filament (propeller), which are assembled in an ordered manner, controlled by well-understood checkpoints [45]. One key feature is the existence of a flagella master regulator $\left(\mathrm{FlhD}_{4} \mathrm{C}_{2}\right.$-class I) that activates class II flagellar genes. These class II genes transcribe the basal body and FT3SS apparatus, along with the sigma factor FliA, which in turn promotes the transcription of the class III genes (for the filament, motor, hook associated and hook proteins, along with the chaperone and chemotaxis proteins) $[46,47]$. Furthermore, transcription is also coupled to assembly, as levels of FliA are modulated by the anti-sigma factor (FlgM), which is secreted upon hook-completion [48-50]. Additionally, given the energetic cost of motility, expression of the master regulator is modulated by many environmental cues that alter gene expression of the $f h D C$ operon or activity of $\mathrm{FlhD}_{4} \mathrm{C}_{2}[51,52]$.

Here, we aimed to capitalise on the fact that upon mechanical shearing or breakage, flagellar continue to secrete unfolded FliC monomers which are transported to the distal growing tip, allowing regrowth under the FliD cap [53-55]. In addition, in the absence of the FliD cap, or other structural proteins (e.g. FlgKL), secretion of FliC monomers into the media without polymerisation occurs $[56,57]$. In addition, the N-terminal secretion signals of FT3SS subunits are well characterised and have 
been exploited to direct non-FT3SS subunits for secretion through the FT3SS in E. coli [29-32] and (their close relatives) Salmonella [34-36]. We aimed to develop an improved, modular FT3SS E. coli strain for high yielding secretion of a range of therapeutic recombinant proteins. Our eventual aim is to surpass the secretion titres reported in other $E$. coli secretion systems, by achieving extracellular secreted titres in the high $\mathrm{mg} \mathrm{L}^{-1}$ range. We hope to accomplish this using controlled secretion to the extracellular space, combined with the absence of cellular contaminants. Here we report progress towards these targets via strain development, secretion signal optimisation, rigorous use of controls, and development of a highthroughput assay to measure FT3SS secretion.

\section{Results}

\section{Establishing a prototype FT3SS secretion strain} and defining optimal parameters for protein expression and secretion

In this study we used E. coli MC1000 as the parent strain, partly for biosafety given its leucine auxotrophy, but also given the presence of an IS5 insertion sequence upstream of $f h D$. This reduces negative transcriptional regulation on $f h D C$, by disrupting promoter binding sites for the negative regulators LrhA and OmpR (for annotated sequence see Additional file 1: Fig. S1) [58-60]. Previous studies of FT3SS dependent protein secretion in $E$. coli employed a $\Delta f l i D$ 'cap-less' strain [29-31, 36]. We also considered alternative strategies, given the potential for this strain to influence and suppress $\mathrm{FlhD}_{4} \mathrm{C}_{2}$ activity via post-translational protein-protein interactions of the FlhDC complex with FliT (the chaperone of FliD) [61, 62]. Specifically, we created a 'HAP-less' $(\triangle f l g K L)$ strain, which would not incur feedback on $\mathrm{FlhD}_{4} \mathrm{C}_{2}{ }^{-}$, but would theoretically decouple secretion from assembly, i.e. as opposed to the $\Delta$ fliD strain where more free FliT would potentially repress $\mathrm{FlhD}_{4} \mathrm{C}_{2}$ activity, and thus flagellar gene expression [61]. In addition, it has also been established that in $\triangle$ flgKL mutants, unpolymerised FliC monomers are secreted into the media, rather than assembling into a filament [56]. To lessen competitive secretion, strains also lacked $f l i C$. We found that the HAP-less and cap-less strains displayed identical growth curve parameters (Additional file 1: Fig. S2). We then compared their ability to export a $39 \mathrm{kDa}$ shortened version of FliC that lacked the central D3 domain (residues 191283) so that it could be easily distinguished from native FliC. This secretion substrate was termed FliC- $\Delta \mathrm{D} 3$ and was inserted into plasmid pTrc99a-FF to create pTrcFliC- $\Delta \mathrm{D} 3$, and expressed by addition of IPTG. This substrate was efficiently secreted (Fig. 1) and also produced a fully motile strain when provided in trans in a $\Delta f l i C$ strain (Additional file 1: Fig. S3).
As shown in Fig. 1a, b when FliC- $\Delta$ D3 was expressed with induction using $0.05 \mathrm{mM}$ IPTG, we observed approximately twofold more FliC- $\Delta \mathrm{D} 3$ (on average $7.4 \mathrm{mg} \mathrm{L}^{-1}$ ) in the secreted fraction of the HAP-less strain in comparison to the cap-less. Notably, we also observed increased amounts of FliC intracellularly in the HAP-less strain (Fig. 1a, c) but found overall that the HAP-less strain was 1.3 times more efficient at secreting protein (secreted FliC- $\Delta \mathrm{D} 3$ as a function of total FliC- $\Delta$ D3, i.e. $7.4 \mathrm{mg} \mathrm{L}^{-1}$ divided by $98 \mathrm{mg} \mathrm{L}^{-1}$ for the HAP-less strain). Based on the absence of additional proteins in the cell supernatant (Fig. 1a-Coomassie), we infer that the improved titre of secreted FliC- $\Delta \mathrm{D} 3$ was due to FT3SS secretion, as cell lysis was not prevalent in either of these strains. We therefore used the HAP-less, $\triangle f l i C \triangle f l g K L$ strain in subsequent experiments as our prototype FT3SS secretion strain.

Before further experimentation, we defined optimal parameters for expression and production of proteins via the FT3SS-assessing that the optimal $\mathrm{OD}_{600}$ for harvest of cells for maximal secretion of FliC- $\Delta \mathrm{D} 3$, is between an $\mathrm{OD}_{600}$ of 1 and 2, i.e. the mid-late exponential phase (Fig. 2a and inset). We then examined the effects of varying the inducer (IPTG) concentration on expression and secretion of FliC- $\Delta \mathrm{D} 3$. We harvested cells at an $\mathrm{OD}_{600}$ of 1.0 and show that $0.05 \mathrm{mM}$ IPTG produced the highest concentration of both intracellular and secreted FliC- $\Delta$ D3 (Fig. 2b), therefore this procedure forms the basis of experiments.

\section{Preliminary improvement of the FT3SS prototype using native substrates}

To establish whether secretion via the FT3SS could be improved from this basal level, we considered a series of mutations that might boost overall flagellar gene expression. We then compared their effect on secretion to a number of negative controls, to establish the absolute specificity of this system. As seen in Fig. 3a, b, use of an flhDC null mutant, with no FT3SS present, resulted in complete lack of FliC- $\Delta \mathrm{D} 3$ secretion even when overproduced in the cytoplasm (by addition of $1 \mathrm{mM}$ IPTG). In parallel we also tested secretion of FliC- $\Delta \mathrm{D} 3$ in a $(\Delta f l i C$ $\triangle f l g K L) \triangle f l g D E$ strain, in which secretion of 'late' filament substrates (i.e. FliC) is abrogated due to the absence of substrate specificity switching [57, 63], and observed a complete lack of secretion in this strain. Further to these controls, we also tested for the presence of the strictly cytoplasmic, GroEL chaperonin protein. Aside from a negligible amount in the $\triangle f l h D C$ strain, the cytoplasmic contaminant GroEL was absent in secreted fractions (Fig. 3c). This demonstrates that cell lysis was not prevalent, and that the two secretion strains are no more 'leaky' that the negative control strains. Together, this confirmed 


\section{a}

\section{FliC- $\Delta$ D3: secreted}

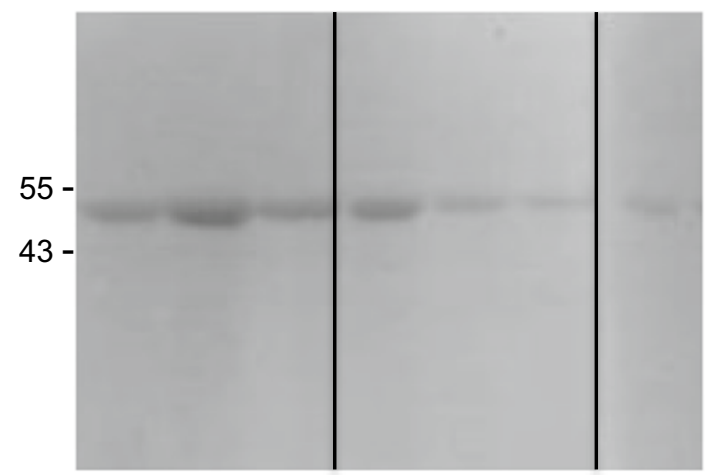

FliC- $\Delta$ D3: intracellular

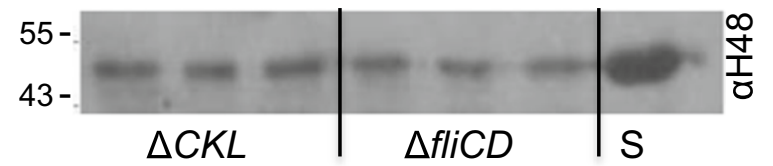

b

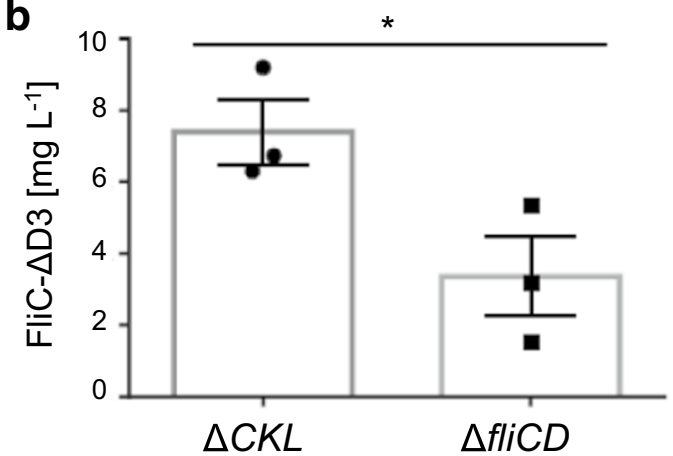

C

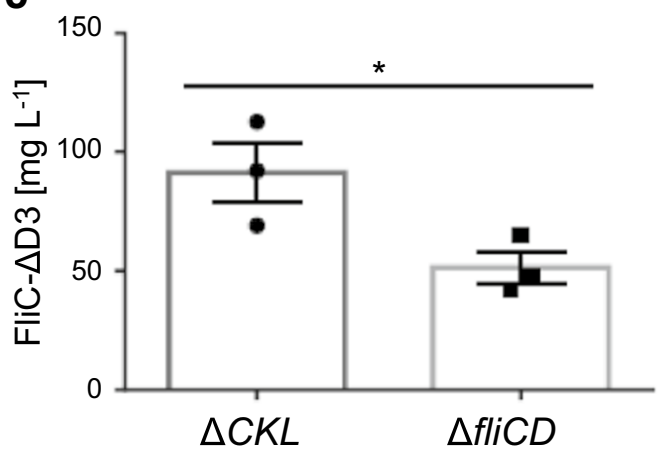

Fig. 1 Comparison of secretion capacity in the HAP-less and cap-less strains. E. coli MC1000 $\triangle$ fliC $\triangle$ flg $K L(\triangle C K L)$ and $\triangle$ fliCD containing the plasmid pTrc-FliC- $\triangle \mathrm{D} 3$ were grown in LB supplemented with $0.05 \mathrm{mM}$ IPTG, and harvested at $\mathrm{OD}_{600}$ 1.5. Samples which represented either $25 \mu \mathrm{L}$ or $400 \mu \mathrm{L}$ culture media were loaded for SDS-PAGE, for intracellular and secreted protein respectively. a Representative images showing the secreted fractions following Coomassie staining, and the intracellular fractions following immunoblotting using an anti-flagellin ( $\mathrm{H} 48$ ) antibody and a HRP secondary. A FliC- $\triangle \mathrm{D} 3$ protein standard (S) was also included, to allow quantification of protein concentration by densitometry (b, c). Quantifications for biological triplicates, \pm SE and individual data points shown, ${ }^{*} p<0.05$ that the presence of FliC- $\Delta \mathrm{D} 3$ monomers in the secreted fraction was due to targeted FT3SS secretion alone.

We then examined the effect of mutations that might upregulate flagellar gene expression. Our initial target was the protein quality control protein, $\mathrm{ClpX}$, a component of the ClpXP protease complex which acts on $\mathrm{FlhD}_{4} \mathrm{C}_{2}$ [64]. In previous studies the removal of $\operatorname{clp} X$ in Salmonella and enterohaemorrhagic E. coli resulted in an accumulation of $\mathrm{FlhD}_{4} \mathrm{C}_{2}$, an increase in the amount of FliC subunits secreted, and increased cell motility [6567]. Here we show that the removal of $c l p X$ from wildtype E. coli $\mathrm{MC} 1000$ cells resulted in an increase in filament proteins and increased motility (Additional file 1: Fig. S4a-d). The removal of $c l p X$ from the prototype strain resulted in an increase in both intracellular and secreted FliC- $\Delta$ D3 (Fig. 3a, b). The secretion efficiency (secreted protein as a proportion of the total (intracellular and secreted) protein) did not alter, however we did measure a 1.6-fold average increase in the titre of secreted protein, and a maximum estimated secretion of $34 \mathrm{mg}$ FliC- $\Delta \mathrm{D} 3 \mathrm{~L}^{-1}$ culture medium achieved from $\Delta f l i C$ $\Delta$ flgKL $\Delta c l p X$ (calculated by comparison to a FliC- $\Delta \mathrm{D} 3$ standard). We also noted that $\Delta f l i C \Delta f l g K L \Delta c l p X$ cells were on average 1.2 times longer $(\mathrm{p}<0.001$. $\mathrm{t}$-test) than $\triangle f l i C \triangle f l g K L$ cells, with a higher abundance of very long cells $(>0.8 \mu \mathrm{m})$ (Additional file 1: Fig. S4e-g). As we detected significantly more $(\mathrm{p}<0.05)$ FlhA in $\Delta$ clpX cells (Fig. 5c), this may suggest that elongated cells harbour a larger number of FT3SS basal bodies, thus allowing increased secretion, though we have no experimental evidence for this at this stage. Of note is that we also produced a $\triangle f l i C \triangle f l g K L \Delta d k s A$ strain, which in contrast to what was anticipated based on published literature [68, 69], did not result in any noticeable increases in FT3SS secretion. As a result, we moved on with the $\Delta f l i C \Delta f l g K L$ $\Delta c l p X$ strain as a Mark II FT3SS strain to test additional strain modifications.

\section{Development of a prototype secretion plasmid and high-throughput assay to measure secretion}

In order to move towards our goal of production and secretion of heterologous proteins via the FT3SS, we designed and tested a synthetic prototype modular vector. This contained elements aimed at optimal secretion of proteins via the FT3SS, alongside their subsequent detection and ultimately purification (FLAG and Streptavidin, TEV protease. See Additional file 1: Fig. S5). These were produced as plasmids in the IP-Free pJEXpress backbone (DNA2.0), with the first 47 amino acids of FliC (the secretion signal [70]), the fliC 5'UTR (which also harbours the native $\mathrm{fliC}$ promoter, thus allowing both T5 based-IPTG inducible, and flagellar mediated (class III, via FliA $[71,72]$ ) gene expression), alongside the $\mathrm{fliC}$ 


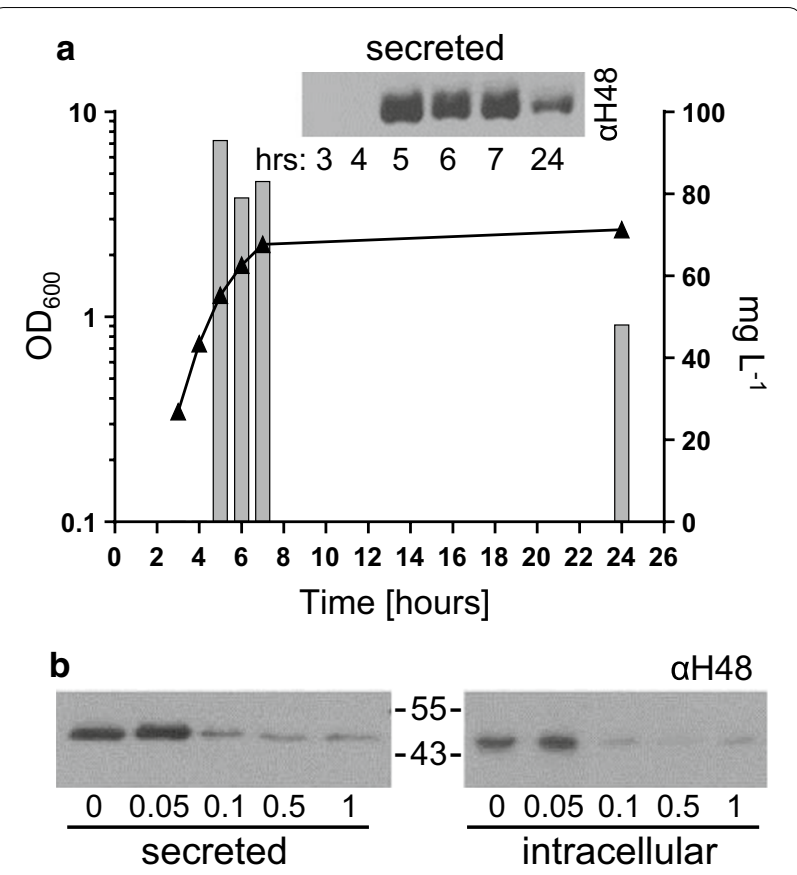

Fig. 2 Optimisation of cell culture induction and harvesting procedure for the Flic- $\triangle \mathrm{D} 3$ protein secretion assay. The 'prototype' $E$. coli MC1000 $\triangle$ fliC $\triangle$ flg $K L(\triangle C K L)$ containing the plasmid pTrc-FliC- $\triangle D 3$ was grown in $100 \mathrm{~mL}$ flask cultures in LB and either a supplemented with $0.05 \mathrm{mM} \mathrm{IPTG}$ and harvested every hour or $\mathbf{b}$ supplemented with $0,0.05,0.1,0.5$ or $1 \mathrm{mM}$ IPTG and harvested at $\mathrm{OD}_{600} 1.0$. Flic- $\triangle \mathrm{D} 3$ was detected by immunoblot as described in Fig. 1a. Samples which represented either $25 \mu \mathrm{L}$ or $300 \mu \mathrm{L}$ culture media were loaded for SDS-PAGE for intracellular and secreted protein respectively. Densitometry analysis allowed quantification of secreted protein, throughout the growth curve. This was repeated to ensure that this corroborated with the general trend plasmid resulting in pJex-fliC47-cutinase, which is predicted to yield a $30.6 \mathrm{kDa}$ peptide.

Following expression of pJex-fliC47-cutinase in the $\triangle f l i C \quad \triangle f l g K L$ strain, both intracellular and secreted cutinase were detected, via the secretion construct incorporated FLAG tag (Fig. 4a). We next developed a simple fluorimetric secretion assay, based on cleavage of 4-methylumbelliferyl butyrate (MUB) by cutinase to yield a fluorescent 4-methylumbelliferone (4-MU) [78]. Cell-free supernatant was mixed with MUB in the presence of an appropriate buffer, and release of 4-MU was measured. This could be qualitatively observed on a UVtransilluminator to allow quick visual screening (Fig. 4b). We also established conditions for a quantitative platereader based version of the assay (excitation $302 \mathrm{~nm}$, emission $446 \mathrm{~nm}$ ). To test the specificity of the assay, pJex-fliC47-cutinase was transformed into negative control strains $(\triangle f l h D C$ and $\Delta f l i C \Delta f l g K L \Delta f l g D E)$ as in Fig. 3. After subtraction of background MUB cleavage no activity was detected in strains containing pJex-fliC47-empty or LB only controls (Fig. 4c). Absence of secretion was verified by immunoblotting of the same samples (Fig. 4d). Reassuringly, we observed increased concentrations of secreted cutinase (twofold higher AU) in the Mark II $\triangle f l i C \Delta f l g K L \Delta c l p X$ strain compared to the $\Delta f l i C \Delta f l g K L$ prototype strain. We used this assay to detect a range of concentrations of secreted cutinase $\left(0.04-0.20 \mathrm{mg} \mathrm{L}^{-1}\right)$, and note that the assay could detect cutinase concentrations is excess of this. With the assay established, it was possible to screen a larger number of strains and secretion signal variants, with the aim of generating a higher capacity, Mark III secretion strain.

\section{Use of the high-throughput cutinase screen to establish an optimised secretion strain}

The MUB-cutinase assay was next utilised to assess the secretion capacity of a number of alternative FT3SS secretion strains. These were engineered to upregulate flagellar expression, or reduce metabolic burden via the deletion of redundant genes. These included the $\operatorname{clp} X$ knockout strain outlined previously, and three additional targets: $\triangle f \lg M N$ (FlgM a negative regulator of class III flagellar gene regulation, and FlgN chaperone for FlgK and regulator of FlgM $[50,79,80]$ ), $\triangle$ fliDST (FliT-an antiFlhD $\mathrm{C}_{2}$ factor and FliST-chaperones of FliCD [61, 81]) and $\triangle m o t A B$ (MotAB responsible for energising flagellar rotation, but not required for secretion [82, 83]). Following their construction and establishing that growth of all strains was comparable to $\Delta f l i C \Delta f l g K L$ (Additional file 1: Fig. S6), the supernatant was analysed for the presence of cutinase via the MUB fluorescence assay (Fig. 5a). Of all the combinations tested, only $\triangle f l i C \triangle f l g K L \triangle m o t A B$ $\triangle f l i D S T$ and $\triangle$ fliC $\triangle$ flgKL $\triangle \operatorname{clpX} \triangle \operatorname{mot} A B$ resulted in 


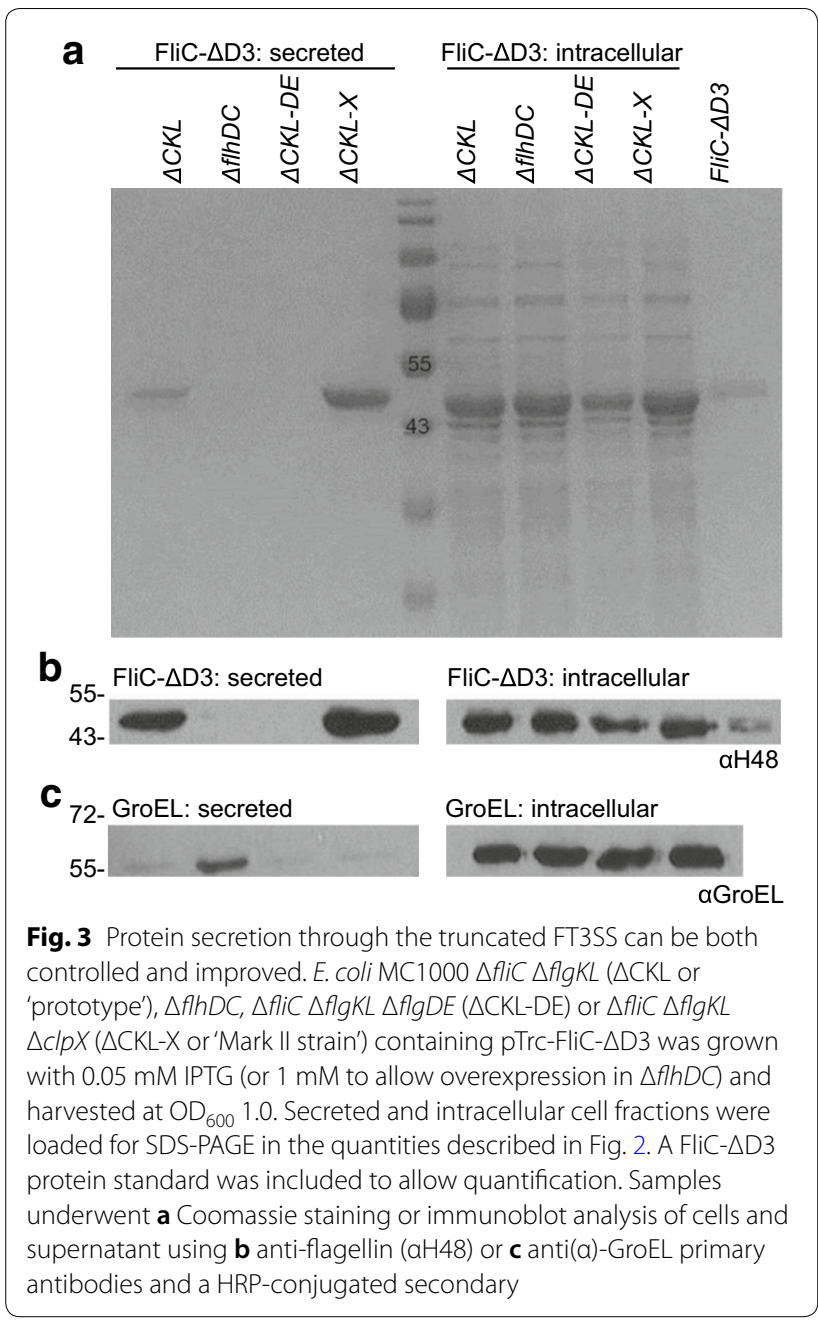

a significant improvement to secretion, in comparison to the original $\triangle f l i C \Delta f l g K L$ strain: 1.64- and 1.67-fold respectively, $(\mathrm{p}<0.05$ and $<0.01)$. To ensure that poor secretion was not a factor of poor cutinase expression, the presence of intracellular cutinase in all strains was confirmed with immunoblotting (Fig. 5a-intracellular).

Having identified high capacity secretion strains that could secrete active fungal cutinase, we now wished to test a human recombinant protein: an E. coli codon optimised version of the gene encoding human ' $\mathrm{CH}_{2}$ ' $\left(\mathrm{CH}_{2}\right)$ $\mathrm{ScFv}$ antibody fragment $(23 \mathrm{kDa}$, donated by J. Pandhal, University of Sheffield $[84,85]$ ), which is used as an adjuvant in human antibody drugs. This was inserted into our modular secretion vector. We compared secretion of $\mathrm{CH}_{2}$ and the native substrate, FliC- $\Delta \mathrm{D} 3$, in the most promising secretion strains, and observed (similarly to cutinase) improved secretion in $\Delta$ fliC $\Delta f l g K L \Delta c l p X$ $\triangle$ mot $A B$ strain: $2.57 \times\left(\mathrm{CH}_{2}\right)$ and $3.75 \times(\mathrm{FliC}-\triangle \mathrm{D} 3)$ over that observed for the prototype strain (Fig. 5b). For both substrates this amounted to a 2.8 -fold improvement to secretion efficiency. In contrast, the $\triangle f l i C \quad \Delta f l g K L$ $\triangle$ motAB $\triangle$ fliDST strain did not perform in a similar manner to cutinase, when secreting $\mathrm{CH}_{2}$ and FliC- $\Delta \mathrm{D} 3$, with no improvement to secretion over the prototype. We thus concentrated on $\Delta f l i C \Delta f \lg K L \Delta \operatorname{clp} X \Delta m o t A B$, as a Mark III strain.

To gain more information on the varying success of these two strains, we used an antibody directed against the FlhA protein (which is present as part of the FT3SS export apparatus) as a proxy indicator of the number of flagellar export apparatus in the cell population. Since its gene expression is under the control of $\mathrm{FlhD}_{4} \mathrm{C}_{2}$, FlhA is also an indicator of total flagellar gene expression. Whole cell lysates were examined by immunoblot and quantified by densitometry analysis (Fig. 5c). Mutant strains representing the individual knockout strategies were also included as controls. Overall, these data indicate that deletion of $c l p X$ results in an increase in FlhA levels by approximately 1.5 -fold in both the $\Delta f l i C \Delta f l g K L$ and $\triangle f l i C$ $\triangle f l g K L \triangle m o t A B$ backgrounds $(\mathrm{p}<0.05)$. In contrast, deletion of motAB alone seems to reduce FlhA levels (0.75fold; $\mathrm{p}<0.01)$. Overall, it is evident that the absence of $c l p X$ in strains upregulates FlhA levels, and by extension, other class II and III genes, which may explain the improvements to secretion we observed.

\section{Improvements to secretion efficiency by secretion signal modification}

In parallel to the studies aimed at strain engineering for increased FT3SS capacity, we also examined the influence of the secretion signal employed in the plasmidbased modular secretion vector. The reasoning here was that the literature reports that the inclusion of the first 47 residues of FliC [70], the $5^{\prime}$ and $3^{\prime} \mathrm{UTRs}$ [29, 30, 35], or a truncated FliC 26-47 construct with either the Salmonella or E. coli version of residues 26-28 [34, 35], can direct export of protein through a truncated FT3SS. All secretion construct (denoted SC) variants were inserted in frame with the cutinase gene, with the predicted size in $\mathrm{kDa}$ shown (Fig. 6). These studies were conducted using the prototype $\triangle f l i C \triangle f l g K L$ strain, with a $\triangle f h D C$ strain and empty vector as negative controls. Expression of the prototype secretion construct (labelled as SC0 here) in the Mark II $\Delta f l i C \Delta f l g K L \Delta c l p X$ strain served as an additional positive comparator. The data show that while all constructs produced cutinase (Fig. 7a), some constructs neither expressed nor secreted well $(\mathrm{SC} 3,5,7)$, while others had low intracellular but significantly higher secreted levels of cutinase (SC1, $\mathrm{p}<0.005)$, or, significantly high intracellular cutinase $(\mathrm{p}<0.001)$ with none secreted (SC8) (see Fig. $7 \mathrm{~b})$. From these data it is possible to infer that the $3^{\prime} \mathrm{UTR}-$ while putatively influencing intracellular stability of 


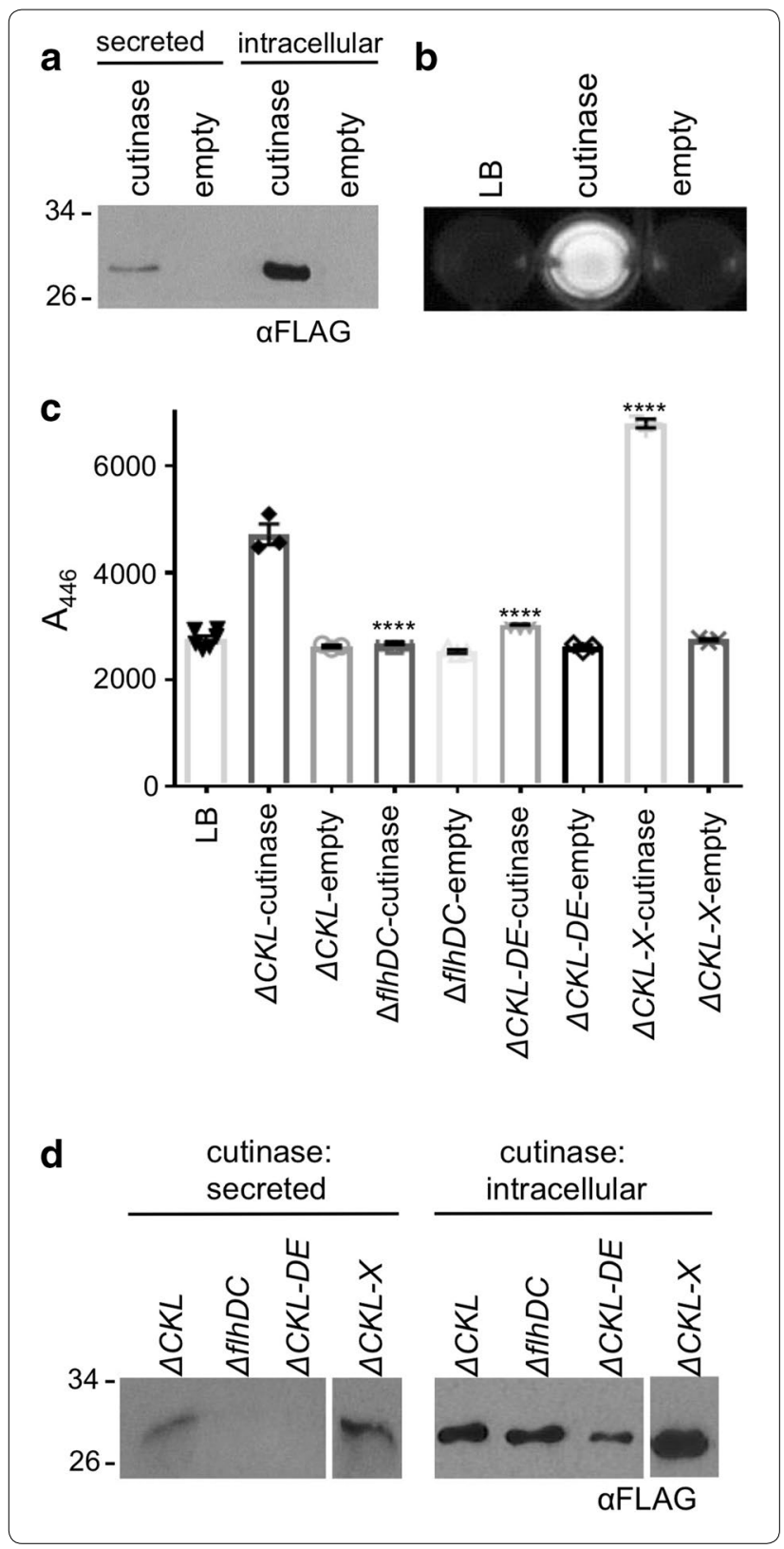

cutinase-seems to actually reduce export $(\mathrm{SC} 3,5,7)$. Whereas the intact $5^{\prime} \mathrm{UTR}$ and FliC $1-47$ alone (SC1) seem to permit the highest levels of secretion, as this exports cutinase at 1.8 -fold higher concentrations than the prototype $(\mathrm{SC} 0)$. This led us to examine the possibility that the FliC $5^{\prime}$ UTR alone, has the ability to direct secretion-as has been indicated by other workers [30]. However, when we inserted the cutinase gene into plasmids containing only the 5 and $3^{\prime}$ UTRs (SC10) or the $5^{\prime} \mathrm{UTR}$ alone (SC11), we observed that despite good expression in all strains (Additional file 1: Fig. S7), cutinase secretion was at least fourfold lower (Fig. 7c).
Fig. 4 Development of a high throughput fluorescence assay to measure protein secretion through the truncated FT3SS. The 'prototype' E. coli MC1000 $\triangle$ fliC $\triangle$ flg KL $(\triangle C K L)$ containing either pJex-flic47-cutinase or pJex-flic47-empty were grown as described in Fig. 3 and prepared for a immunoblot with the anti-FLAG-HRP (aFLAG) antibody (where samples representing either $15 \mu \mathrm{L}$ or $300 \mu \mathrm{L}$ culture media for intracellular and secreted protein respectively were loaded onto the SDS-PAGE) (b) or florescence assay: $40 \mu \mathrm{L}$ supernatant was added to $160 \mu \mathrm{L}$ MUB substrate in a 96 well plate. Following incubation for $30 \mathrm{~min}$ at $30^{\circ} \mathrm{C}$, samples were visualised under UV light. c, d E. coli strains $\triangle$ fliC $\triangle$ flgKL ( $\triangle C K L$ or 'prototype'), $\triangle$ fliC $\triangle$ flgKL $\triangle c l p X$ ( $\triangle C K L-X$ or 'Mark II strain'), $\triangle$ flhDC and $\triangle$ fliC $\triangle$ flgKL $\triangle$ flgDE ( $\triangle C K L-D E)$ harbouring the cutinase expressing or empty vector plasmid were grown and $\mathbf{c}$ prepared for MUB secretion assay as described above; however following incubation, fluorescence was measured in a plate reader (excitation $302 \mathrm{~nm}$, emission $446 \mathrm{~nm}$ ). Results from one biological replicate, with three technical repeats. \pm SE and individual data points shown. Two-way ANOVA (variables: strain and plasmid) and Tukey's multiple comparison test: ${ }^{* * *} p<0.001$. d Representative immunoblot of secreted and intracellular fractions prepared from the same cell cultures

With this evidence, the plasmid harbouring SC1 was taken forward (for the construction of a Mark IV secretion strain) as the best candidate for increased secretion through the FT3SS.

\section{Confirmation that the 'late' FliC signal outperforms an 'early' hook-cap signal}

As a final step to investigate the optimal secretion signal, we compared secretion of our 'late' FliC signal with early flagellar substrate signal sequences, namely the hook (FlgE) and hook-cap (FlgD) proteins. In order to compare these signals, we constructed cutinase harbouring secretion signal sequence variants using the first 100 amino acids of FlgD or FlgE (Additional file 1: Fig. S8a) for testing in both an early-locked, hook-less $[\triangle f l i C \Delta f l g K L$ $\triangle f l g D E(\Delta c l p X)]$, and a substrate switched $[\Delta f l i C \Delta f l g K L$ $(\Delta c l p X)]$ background. The FlgE signal did not permit secretion in either strain, and the FlgD signal was four- to fivefold less effective at export than the FliC signal (Additional file 1: Fig. S8b). This indicated that despite the streamlined nature of the hook-less strain, it is in fact less efficient for secretion than the HAP-less strain. We did observe low-levels of cutinase secretion with SC13 (FlgD signal) in the $\Delta f l i C \Delta f l g K L \Delta c l p X$ strain, presumably due to higher expression of secretion apparatus, but still at a much lower level (fourfold) than with the intact FliC signal (SC1).

\section{Examination of combined strain and secretion signal improvements}

Finally combination of the improvements to the chassis and modular secretion vector were investigated in comparison to the prototype versions. Both strains contained 
Fig. 5 Screening for strains which are high capacity secretors of recombinant cutinase, and additional substrates. a The 'prototype' $E$. coli MC1000 $\triangle$ fliC $\triangle$ flgKL $(\triangle C K L)$ strain with additional combinations of: $\triangle$ motAB (mot) $\triangle$ flgMN (MN) $\triangle$ fliDST (DST) or $\triangle c l p X(X)$, which contained pJex-flic47-cutinase were grown with 0.05 mM IPTG and harvested at $\mathrm{OD}_{600}$ 1.0. Secreted fractions (Sn) were analysed by the MUB florescence assay as described in Fig. 4c. Results from three biological replicates were normalised to $\triangle C K L, \pm S E$ shown, one-way ANOVA: $p \leq 0.001$. Tukey's multiple comparison test to $\triangle C K L:{ }^{*} p \leq 0.05,{ }^{* *} p \leq 0.01$. Representative immunoblot of the intracellular fraction from $15 \mu \mathrm{L}$ cell culture shown below. $\mathbf{b}$ E. coli $\triangle C K L$ ('prototype'), $\triangle C K L-X-m o t$ (Mark III strain) and $\triangle C K L-$ mot-DST expressing pJex-flic47- $\mathrm{CH}_{2}(+$, upper), pTrc-FliC- $\Delta \mathrm{D} 3$ (+, lower), or empty vector (-) were grown (as above) and prepared for immunoblot using either an anti-FLAG-HRP (aFLAG) antibody (upper) or an anti-flagellin (aH48) antibody and a HRP conjugated secondary (lower). The equivalent of $15 \mu \mathrm{L}$ cell culture was loaded for intracellular fractions, and either 300 or $60 \mu \mathrm{L}$ for the secreted fractions (for $\mathrm{CH}_{2}$ and FliC- $\triangle \mathrm{D} 3$ respectively), along with the relevant protein standard to allow quantification. $\mathbf{c}$ Whole cell fractions underwent immunoblot with an anti-FlhA antibody (aFlhA), results from densitometry are presented relative to $\triangle C K L$. Five biological repeats, \pm SE and individual data points shown. One-way ANOVA: $p<0.005$ and Tukey's multiple comparison test: ${ }^{*} p<0.05$, ${ }^{* *} p<0.01$

more intracellular cutinase following expression of SC1 over the SC0 prototype (Fig. 8a). Additionally there was more intracellular cutinase in the Mark III strain than the prototype-irrespective of secretion construct. Detection of the FLAG-tag by immunoblotting allowed visualisation of secreted cutinase by a means other than the MUB assay. In agreement with previous results (Fig. 5a, b), the Mark III strain secreted a higher concentration of substrate in comparison to the $\Delta f l C \Delta f l g K L$ strain when expressing the prototype secretion construct (Fig. $8 \mathrm{~b}, \mathrm{~d}$ ), this translated to a 3.83-fold improvement in secretion efficiency (Fig. 8a, b). However, the highest concentrations of secreted cutinase were seen when either strain expressed $\mathrm{SC} 1$, with $\triangle$ fliC $\triangle$ flgKL $\Delta c l p X \Delta \operatorname{mot} A B$ resulting in the highest. Given the low abundance of GroEL in $\triangle$ fliC $\triangle$ flgKL $\triangle c l p X \triangle m o t A B$ cell supernatant (Fig. 8c), we show that the increase in extracellular cutinase in this modified strain is not due to cell lysis or membrane leakage. In fact the lower level of cytoplasmic leakage in $\triangle f l i C \Delta f \lg K L \Delta c l p X \Delta m o t A B$ suggests that the $\operatorname{clp} X$ allele may in fact destabilise the cell envelope, although this would require further investigation. We also note that the $\alpha$-GroEL antibody is very sensitive and the Coomassie stained gel (not shown) did not indicate cell leakage in the $\triangle f l i C \triangle f l g K L$ strain either. Using the same samples, a MUB protein secretion assay was carried out (Fig. 8e). The improvement attributed to the optimised strain $(\triangle$ fliC $\triangle$ flgKL $\Delta c l p X \Delta \operatorname{mot} A B)$ was 7.68 -fold, and for the secretion construct (SC1) 15.70. Upon combination (Mark IV strain) these improvements were additive, resulting in a 23.78-fold increase in fluorescence in

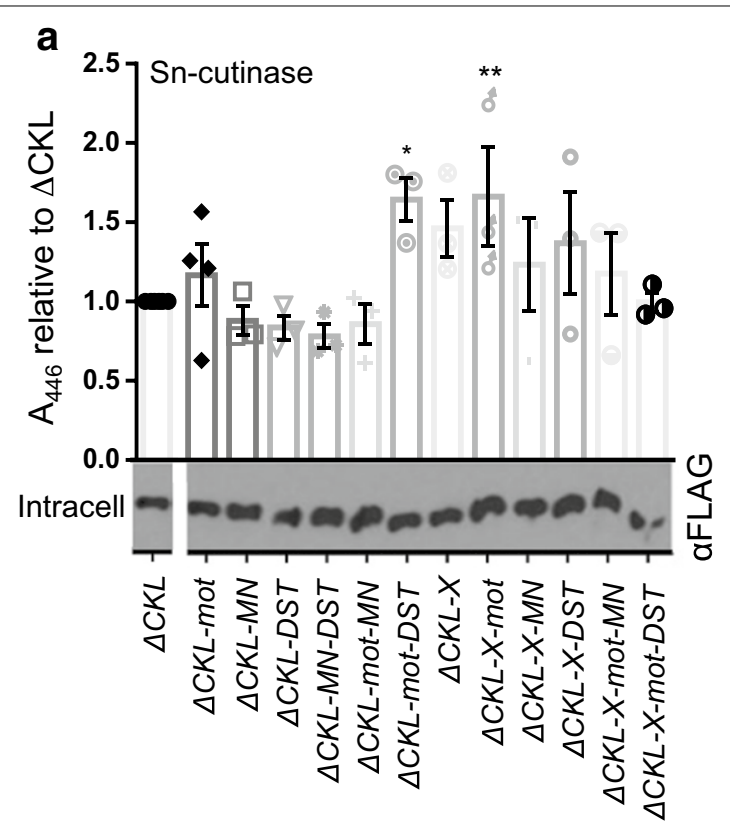

b
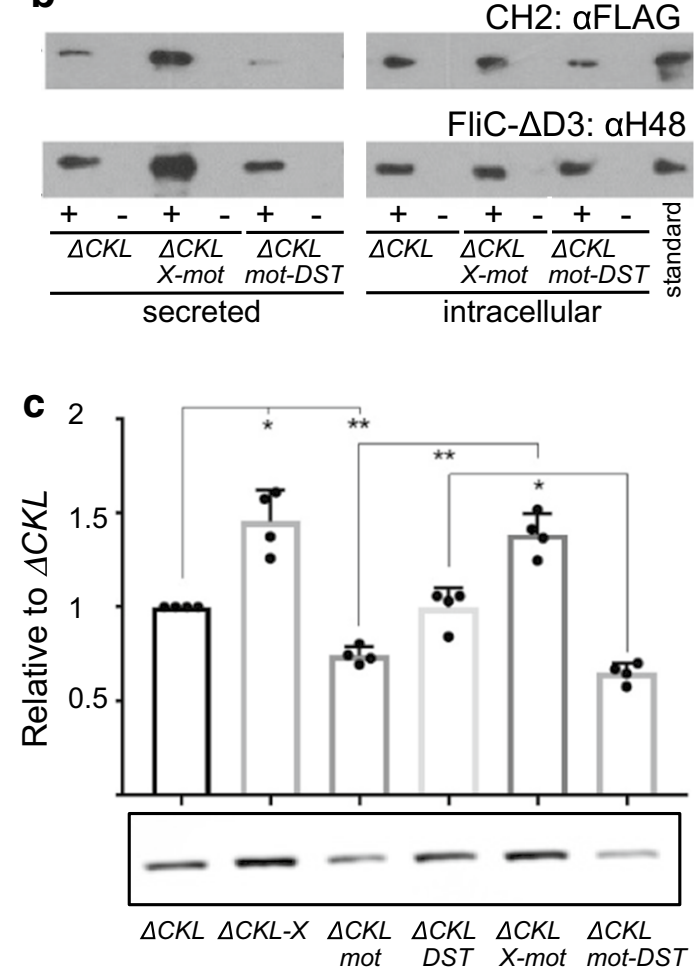

comparison to the prototypes (all $\mathrm{p}<0.001$ ). Densitometry analysis of secreted cutinase measured by immunoblotting (Fig. 8a, b), showed that the strain was 5.64 times more efficient at secreting cutinase than the prototype. Despite immunoblotting determining the combined fold change in the Mark IV strain to be less pronounced 


\begin{tabular}{|c|c|c|c|c|c|}
\hline \multirow[b]{2}{*}{ sco } & \multirow[b]{2}{*}{ 5'UTR } & \multirow[b]{2}{*}{ Flic47 } & \multirow[b]{2}{*}{ cutinase } & & \multirow{2}{*}{$\begin{array}{l}\text { kDa } \\
30.7\end{array}$} \\
\hline & & & & 3'UTR & \\
\hline SC1 & $5^{\prime}$ UTR & Flic47 & cutinase & & 30.7 \\
\hline \multicolumn{2}{|l|}{ SC2 } & Flic47 & cutinase & 3'UTR & 30.7 \\
\hline \multicolumn{2}{|l|}{ SC3 } & Flic47 & cutinase & & 30.7 \\
\hline \multicolumn{2}{|l|}{ SC4 } & FliC 26-47 & cutinase & 3'UTR & 27.8 \\
\hline \multicolumn{2}{|l|}{ SC5 } & Flic 26-47 & cutinase & & 27.8 \\
\hline \multicolumn{2}{|l|}{ SC6 } & FliC Sol 26-47 & cutinase & 3'UTR & 27.8 \\
\hline \multicolumn{2}{|l|}{ SC7 } & FliC Sal 26-47 & cutinase & & 27.8 \\
\hline \multicolumn{2}{|l|}{ SC8 } & & cutinase & 3'UTR & 25.8 \\
\hline \multicolumn{2}{|l|}{ SC9 } & & cutinase & & 25.8 \\
\hline \multicolumn{2}{|l|}{ SC10 } & 5'UTR & cutinase & 3'UTR & 25.8 \\
\hline \multicolumn{2}{|l|}{ SC11 } & 5'UTR & cutinase & & 25.8 \\
\hline \multicolumn{6}{|c|}{$\begin{array}{l}\text { Fig. } 6 \text { Schematic of secretion signal variants. The prototype secretion construct (SCO), and variations (SC1-SC11. Note that SC1 contributes to the } \\
\text { 'Mark IV'improvement) are depicted along with the predicted size of the protein product (kDa). All secretion constructs harbour cutinase, along } \\
\text { with combinations of the } 3^{\prime} \cup T R, 5^{\prime} \cup T R \text {, the } 1-47 \text { residue FliC secretion signal, or the truncated secretion signal (residues } 26-47 \text { ) with the native E. } \\
\text { coli or S. typhimurium codon usage. Construction of these plasmids is outlined in Additional file 1: Fig. S5 and Table S2 }\end{array}$} \\
\hline
\end{tabular}

(Fig. 8d), the overall trend is consistent with the MUB fluorescence assay (Fig. 8e). The Mark IV strain had an average titre of $0.16 \mathrm{mg} \mathrm{L}^{-1}$ secreted cutinase (highest $0.19 \mathrm{mg} \mathrm{L}^{-1}$ ) (Fig. 9).

\section{Testing secretion of a range of recombinant proteins of human origin}

Finally we investigated secretion of a number of pharmaceutically relevant, human proteins in the Mark IV FT3SS strain. These included E. coli codon optimised versions of, the aforementioned $\mathrm{CH}_{2} \mathrm{ScFv}$ fragment, and also human growth hormone (hGH) and thioredoxin (TrxA)-both of which were kindly gifted following an ongoing collaboration with FUJIFILM Diosynth Biotechnologies, UK. Genes were PCR amplified with EcoRI and Pst I restriction site ends and inserted into the SC1 harbouring plasmid. All were secreted into the media, with respective average titres of $0.25,0.15$ and $0.21 \mathrm{mg} \mathrm{L}^{-1}$ from an $\mathrm{OD}_{600} 1.0$ culture (Fig. 9, Additional file 1: Fig. S9).

\section{Discussion}

Despite the clear benefits to protein production, to date, true secretion of recombinant protein by bacterial expression systems into the media is only possible in the $\mathrm{mg} \mathrm{L}^{-1}$ cell culture range, even in high density culture [19-21]. For commercial use this requires improvement, especially when compared to eukaryotic expression organisms-such as Pichia which can reach $15 \mathrm{~g} \mathrm{~L}^{-1}$ [22]. We focus on an $E$. coli chassis, due to its preferential use in IB, for a host of beneficial reasons. In this study, we set out to engineer an $E$. coli with the ability to secrete recombinant protein into the extracellular media, in one direct step. A clear candidate for this was the one step FT3SS, and while recombinant protein has been secreted through the FT3SS previously [29-31, 34, 36], we aimed to make improvements to improve secretion capacity, without leakage, though strain engineering and design of a modular secretion and purification system.

We established that a prototype $\Delta f l i C \Delta f l g K L$ strain outperformed a $\triangle f l i C D$ strain (as utilised in other studies [29-31], in both protein production and secretion (Fig. 1). One explanation might be that FliD binds FliT, and so in the FliCD strain, more FliT is free to interact with, and suppress $\mathrm{FlhD}_{4} \mathrm{C}_{2}$ activity, thus reducing FT3SS expression and secretion [61]. In contrast removal of FlgKL frees up the chaperone FlgN to promote translation-coupled secretion of FlgM-further raising expression of FT3SS components (including the $\mathrm{fliC}$-UTR harbouring modular secretion construct) [80], but whether this occurs in E. coli is not clear at present. We next investigated whether strain engineering could improve secretion, and found that removal of $\operatorname{clpX}$ (a component of the ClpXP protease complex), which is known to actively bind to, and degrade $\mathrm{FlhD}_{4} \mathrm{C}_{2}$ [64], improved the yield of 
Fig. 7 Comparison of expression and secretion in secretion signal variants. a, b The 'prototype'E. coli $\triangle$ fliC $\triangle$ flg $K L(\triangle C K L)$ harbouring either pJex-flic47-empty or the secretion signal variants SC0-SC9 (see Fig. 6), along with $\triangle$ flhDC and $\triangle$ fliC $\triangle$ flgKL $\triangle C l p X(\triangle C K L-X$ or 'Mark II strain') expressing SCO were grown and harvested as in Fig. 3. a Intracellular fractions were prepared for immunoblotting (plus densitometry analysis: representative image shown), and $\mathbf{b}$ secreted fractions for MUB secretion assay, as described in Fig. 4a and c respectively. Three biological repeats, normalised to $\triangle \mathrm{CKL}-\mathrm{SCO}, \pm \mathrm{SE}$ and individual data points shown. One-way ANOVA (for SCO-SC9 expressing strains only) $p<0.001$ and Tukey's multiple comparison test (to $\triangle \mathrm{CKL}-\mathrm{SCO}$ ): ${ }^{* * *} \mathrm{p}<0.001,{ }^{* * *} \mathrm{p}<0.005$. $\mathrm{c}$ The absence of the 47 residue FliC signal, with the presence of the fliC $5^{\prime} \cup T R$ was investigated in $\triangle C K L, \triangle C K L-X$ and $\triangle A h D C$ compared to SC1. Procedure as described for Fig. 7b. Two biological replicates, \pm SE and individual data points shown

secreted FliC by 1.6 -fold, to $34 \mathrm{mg}$ FliC- $\Delta \mathrm{D} 3 \mathrm{~L}^{-1}$ culture medium at $\mathrm{OD}_{600} 1.0$ (Fig. 3). This became our Mark II strain. We also show total absence of FliC- $\Delta \mathrm{D} 3$ in the secreted fractions of FT3SS null strains, along with very low abundance of cytoplasmic contamination (absence of GroEL) (Fig. 3). This observation is consistent for recombinant proteins (Fig. 4d). Furthermore we show that, in the absence of the FliC secretion signal peptide, protein is not exported (Fig. 7b, c and Additional file 1: Fig. S7). Combined, this demonstrates that in our system, the truncated FT3SS shows excellent selectivity and that leakage is not prevalent.

Development of a high-throughput, enzyme based, secretion assay (Fig. 4) enabled us to screen a range of engineered strains and secretion signal constructs (Figs. 5, 7). As enzyme activity requires correct protein folding, the assay also highlights that secreted heterologous cutinase correctly folds in the extracellular media, thus allowing functionality. This is very attractive when considering the proposed biotechnological applications of this truncated FT3SS secretion platform. Through this screen we established the $\triangle$ flgKL $\triangle$ fliC $\triangle \operatorname{clpX} \triangle m o t A B$ as the superior (Mark III) secretion strain (Fig. 5). Several lines of evidence supported that $\operatorname{clpX}$ deletion has a positive effect on secretion through the FT3SS [64-67]. Further to this, we observed increased filament production and motility in $\Delta c l p X$ cells in a wild-type background (Additional file 1: Fig. S4), suggesting increased flagellar gene expression. We confirmed this notion in our truncated secretor strain, as more FlhA was detected in $\Delta c l p X$ mutants (Fig. 5c), suggesting an increase in the number of basal bodies (secretion apparatus). In contrast, the concentration of FlhA was not increased in motAB mutants, indicating that improved secretion in these strains was not due to higher abundance of secretion apparatus. A probable explanation is that this strain has reduced drain a

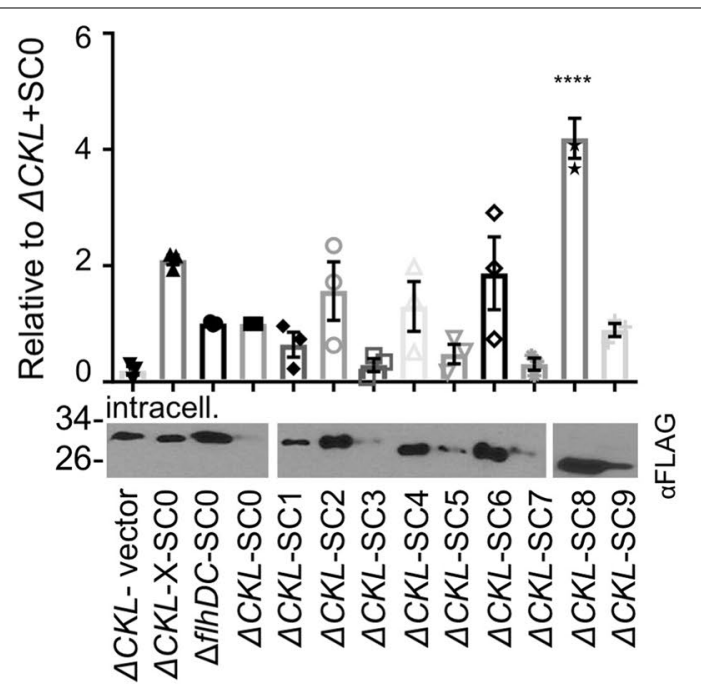

b

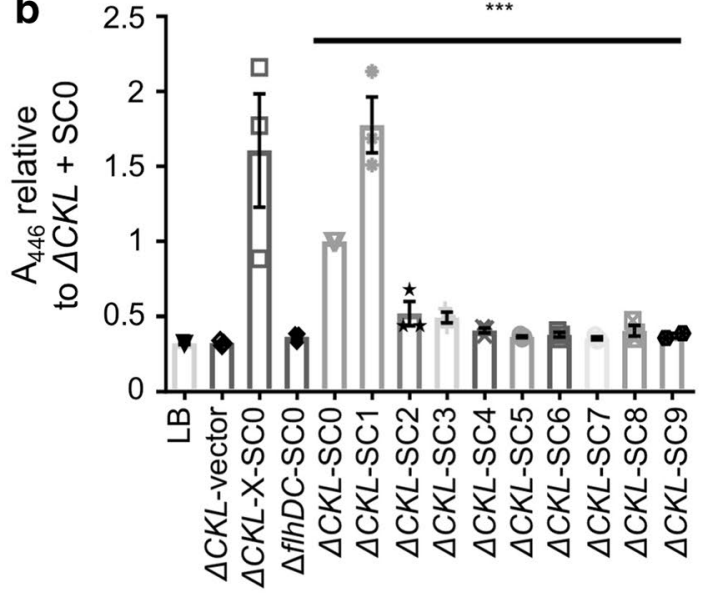

C

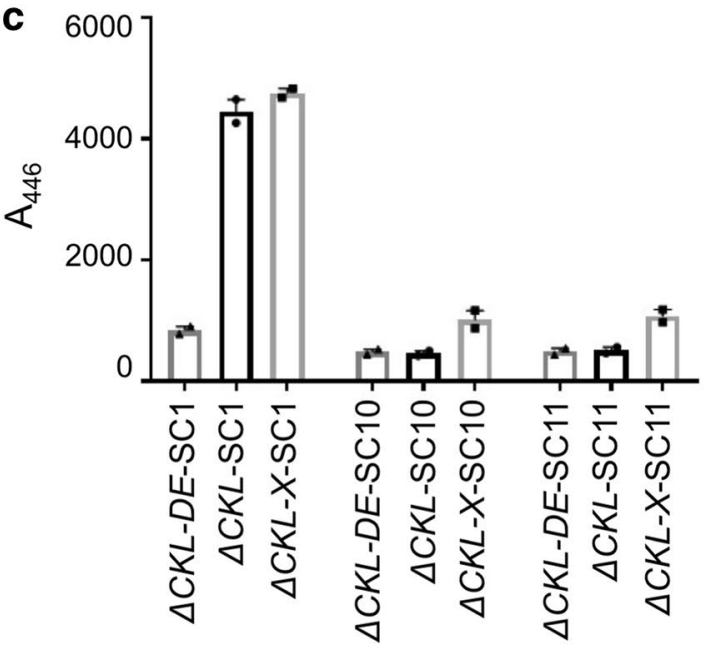


Fig. 8 Cutinase expression and secretion: comparing the prototype, and most improved, strains and secretion constructs. The E. coli 'prototype' $\triangle$ fliC $\triangle$ flgKL ( $\triangle C K L)$ or 'Mark III strain' $\triangle$ fliC $\triangle$ flgKL $\triangle c l p X$ $\triangle m o t A B(\triangle C K L-X-m o t)$ expressing either the prototype (SC0), improved (SC1) modular secretion vector, or pJex-flic47-empty (empty), were grown as described in Fig. 3. Note that $\triangle C K L-X-m o t$ expressing SC1 is our 'Mark IV strain'. Both intracellular and secreted fractions underwent immunoblot analysis using either, an anti-FLAG-HRP (aFLAG) antibody to detect $\mathbf{a}$ intracellular and $\mathbf{b}$ secreted cutinase, or c anti-GroEL and a HRP secondary antibody to detect cytoplasmic protein contamination. Samples representing $15 \mu \mathrm{L}$ and $300 \mu \mathrm{L}$ cell culture were loaded for intracellular and supernatant samples, respectively. $\mathbf{d}$ Densitometry analysis was carried out on aFLAG probed, secreted fractions (Fig. 8b: representative image) of three biological replicates, normalised to $\triangle \mathrm{CKL}-\mathrm{SCO}, \pm \mathrm{SE}$ and individual data points shown. One-way ANOVA, $\mathrm{p}<0.005$ and Tukey's multiple comparison test (to $\triangle \mathrm{CKL}-\mathrm{SCO}$ ): ${ }^{* * *} p<0.005,{ }^{* *} p<0.01,{ }^{*} p<0.05$. e Supernatant was also prepared for MUB protein secretion assay as described in Fig. 4c. Six biological replicates, normalised to $\triangle \mathrm{CKL}-\mathrm{SCO}, \pm \mathrm{SE}$ and individual data points shown. Two-way ANOVA, $p<0.001$ and Tukey's multiple comparison test (to $\triangle \mathrm{CKL}-\mathrm{SCO}$ ): ${ }^{* * *} \mathrm{p}<0.001$

on the proton motive force [82, 83], which would usually provide energy to drive flagellar rotation [86, 87], but also has implications for secretion and growth.

We also established, surprisingly, that combining the fliDST mutation with the Mark III $\triangle$ flgKL $\Delta$ fliC $\Delta c l p X$ $\triangle m o t A B$ strain increased secretion of cutinase, but not other proteins (Fig. $5 \mathrm{~b}$ ), indicating that there may be some protein specific factors in determining secretion capacity. In fact the removal of fliDST, or flgMN were generally not beneficial to secretion. This may be attributed to the fact that there are contrasting reports on the effect of $\mathrm{FlgM}(\mathrm{N})$ deletion on flagellar expression in the literature $[50,79]$. This is complicated by the fact that, FliS also binds FlgM prior to fliA expression, suppressing secretion of FlgM upon hook-basal body completion [88], while removal of FliDST per se has been shown to result in an increase in secreted FlgM [89]. In addition, $\mathrm{FlgN}$ is also implicated here, as a positive regulator of FlgM translation [80], further complicating this picture, and making these data both hard to predict and interpret.

We show that a construct containing the $5^{\prime} \mathrm{UTR}$ and FliC1-47 secretion signal (SC1) was the most efficient for secretion of recombinant proteins (Fig. 7b). In agreement with previous work [30,33], we did not find inclusion of the $3^{\prime}$ UTR to be necessary for secretion-as an extension to this, we also show that exclusion of the $3^{\prime}$ UTR dramatically increases secretion, despite potentially reducing internal levels (Fig. 7a). An explanation may be linked to the evidence that the $3^{\prime}$ UTR influences levels and a Intracellular

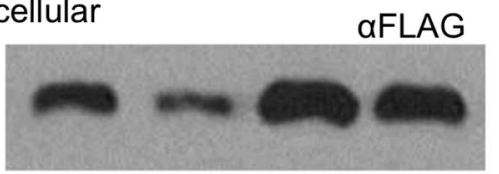

b Secreted

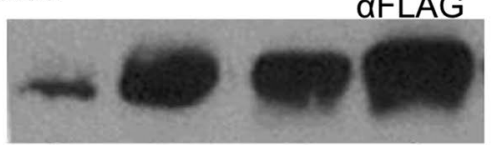

C Cytoplasmic contamination aGroEL

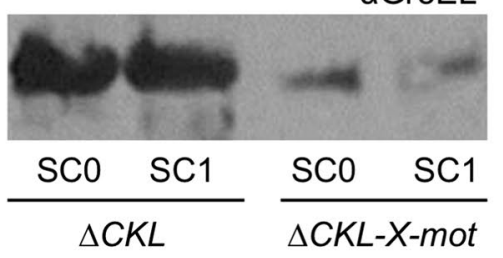

\section{d Densitometry of Secreted (8b)}

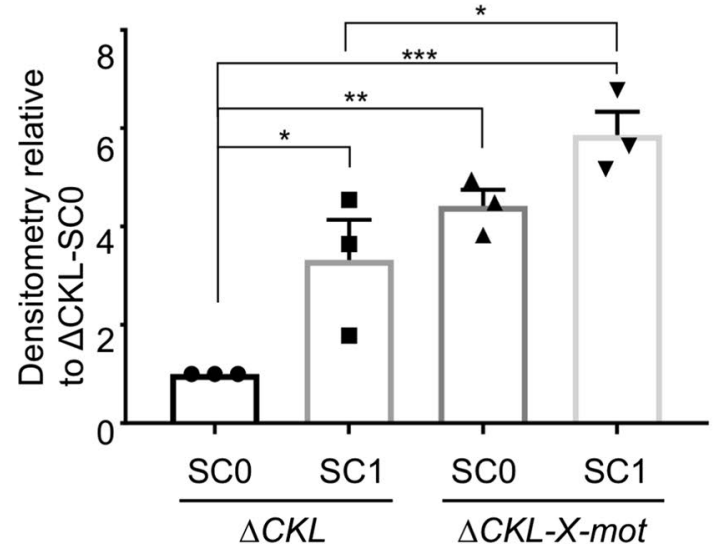

e MUB secretion assay

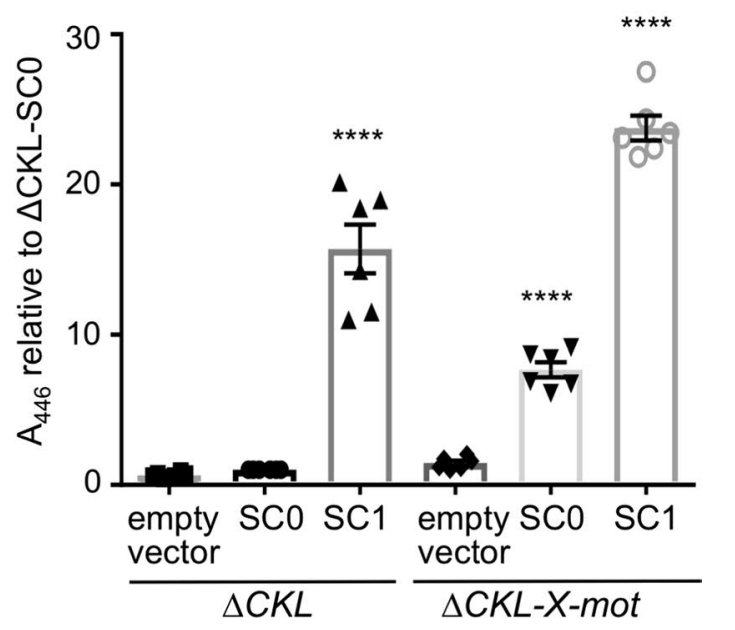




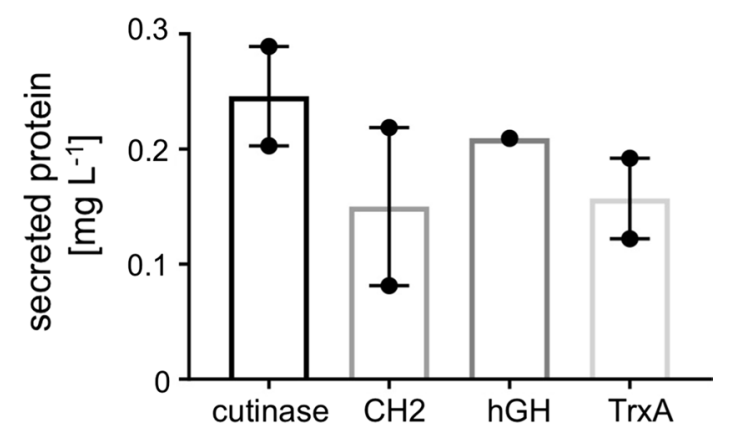

Fig. 9 Secreted titres of a range of substrates through the optimised Mark IV secretion strain. E. coli $\triangle$ fliC $\triangle$ flgKL $\triangle c l p X \triangle$ motAB expressing plasmid based SC1 (Mark IV strains), with either cutinase, $\mathrm{CH}_{2}, \mathrm{hGH}$ or TrxA cargo, were grown as outlined in Fig. 3 and prepared, along with a relevant protein standard (exception: cutinase, where a hGH standard was utilised), for immunoblot detection with anti-FLAG-HRP (aFLAG). The concentration of secreted protein was then quantified by densitometry analysis. Two biological replicates (with the exception of $h(H), \pm S E$ and individual data points shown

stability of the fliC mRNA [90], which in turn has been shown to reduce FlgM secretion [67]. If this is affected by the $3^{\prime}$ UTR region specifically, then this could explain improved secretion in the absence of the $3^{\prime} \mathrm{UTR}$, as FlgM might be more readily secreted from the FT3SS-however at this time we have no evidence to support this theory. In contrast, the $5^{\prime} \mathrm{UTR}$ and FliC1-47 are able to both direct secretion and ensure adequate protein expression. One reason for this might be that the signal peptide confers some level of solubility or reduces formation of inclusion bodies-though again we have not tested this directly. Notably, our evidence (Fig. 7b, Additional file 1: Fig. S7) does not match that of other reports where the FliC 5'UTR [30, 31], or 26-47 residues of the FliC signal alone [34, 35], direct efficient secretion in E. coli. Neither does it match evidence that the $5^{\prime}$ UTR is not necessary for secretion [35], and we can only attribute these differences to potential variances in strain background or experimental conditions. It would seem that modification of the secretion signal had a larger effect on secretion capacity than the strain improvements (15.70- and 7.68-fold improvements respectively). Most compelling, was our finding that upon combination, these improvements have an additive effect on the secretion capacity of the FT3SS (Fig. 8). The overall 23.78-fold improvement to cutinase secretion through the FT3SS is a step-forward in terms of moving towards an E. coli strain capable of high capacity secretion of recombinant protein into the extracellular media, in one step.

In our lab, the best secreted yield of protein achieved (with cell density $\mathrm{OD}_{600}<1.5$ ) in our truncated FT3SS (maximum of $240 \mathrm{mg} \mathrm{L}^{-1}$, average $80-90 \mathrm{mg} \mathrm{L}^{-1}$, of FliC$\triangle D E 3$ secreted into the extracellular media), surpasses that reported for alternative E. coli systems, which also enable secretion into the media. For example in the T1SS: typically in the $\mu \mathrm{g} \mathrm{L}^{-1}$ range, but up to $3 \mathrm{mg}^{-1}$ OD unit cell culture at high cell density [23-28, 91] and FT3SS $\left(\triangle f l i C D\right.$ ): up to $12 \mathrm{mg} \mathrm{L}^{-1}$ (although under unspecified high density cell culture conditions, [30]). We also exceed reported yields achieved for secretion into the $E$. coli periplasm by the type II secretion system at low cell density $\left(30-60 \mathrm{mg} \mathrm{L}^{-1}[13,14]\right)$, without the requirement for periplasmic extraction or the risk of proteolytic enzymes compromising protein quality.

However as we are proposing the use of our strain as a secretion platform in a biotechnological context, we finally set out to investigate the performance of the Mark IV strain when secreting a broad range of industrial and pharmaceutically relevant recombinant proteins. At low cell density $\left(\mathrm{OD}_{600} 1.0\right)$ we achieved average yields of $0.16,0.25,0.15$ and $0.21 \mathrm{mg} \mathrm{L}^{-1}$ for cutinase, a $\mathrm{CH}_{2}$ $\mathrm{ScFv}$ fragment, human growth hormone and thioredoxin respectively (Fig. 9). The secreted titres we report for heterologous protein are lower than those which we measure for native protein (FliC- $\triangle \mathrm{DE} 3)$. This was anticipated, as aside from a small truncation, FliC- $\triangle \mathrm{DE} 3$ is a natural substrate of the FT3SS, whereas the heterologous proteins are non-native to both the organism and the secretion system. We acknowledge that our titres of heterologous protein are lower compared to other bacterial systems (where up to $50 \mathrm{mg} \mathrm{L}^{-1}$ was achieved) $[20,21]$. However our results are still compelling, given that (unlike the majority of literature examples) we have achieved these titres from (1) culture supernatant, (2) at low cell density in E. coli, and (3) showed excellent control of secretion to the extracellular space, with no evidence for cell leakage. When comparing our final Mark IV strain to other strains that meet the majority of these credentials, our current strain secretes around four times less heterologous protein than the best titre reported in the T1SS (cell density unclear) [27], and around 50 times less than an alternative FT3SS system (carried out at a higher cell density and with different proteins) [30].

To match these reported titres in the future, we aim to further boost the titres of secreted protein, with a modified cell culture strategy and more strain engineering. For example, while our supernatant was harvested at a maximum cell density of $\mathrm{OD}_{600} 1.5$; it is noted that transfer to high cell density culture $\left(\mathrm{OD}_{600}>180\right)$ can greatly improve yields [14]. Indeed we have begun to test these strains at higher cell density in bioreactors with no obvious growth defects (unpublished data). Finally, the modular secretion vector has not only been optimised to 
enable high levels of expression (with the removal of the $3^{\prime}$ UTR), and flexibility of protein cargo, but also serves as a versatile platform technology which could be easily adapted for specific applications, i.e. by exchanging the purification or antigen tags. We are currently focussing on how the modular secretion vector performs in terms of recovery of purified protein, free of the accessory tags.

\section{Conclusions}

We have used a combinatorial approach, incorporating strain design and a genetic modular secretion vector, to achieve improved extracellular titres, of a range of biotechnologically relevant protein products, by secretion through a truncated E. coli FT3SS. This may enable simplified downstream processing of higher quality product, free of cellular contaminants, all of which are of great interest to the biopharmaceutical and IB communities. Furthermore, this opens up the possibility of cell cultures that secrete protein continuously, without the need to sacrifice cell culture to retrieve protein product. During development of the truncated secretion construct, a number of findings provided new information on the roles of the secretion signal peptide and UTRs of FliC monomers. We also introduce a high-throughput assay, enabling quick and accurate measurement of the secretion output of truncated FT3SS strains. We are currently using this in inverse genetic engineering approaches to identify factors that might boost secretion further. We suggest that the body of this work serves as a pilot feasibility study, and are working on further improvements (high cell density culture, purifying recombinant protein from the media), with which we envision that our FT3SS secretion platform could become a forerunner for use in the production of biopharmaceuticals and IB products.

\section{Materials and methods}

\section{Bacterial strains and growth conditions}

E. coli $\mathrm{MC} 1000$ was used for the construction of all mutants in this work (Additional file 1: Table S1). E. coli strain MG1655 clpX::Tn5 $\left(\mathrm{Km}^{R}\right)$ was kindly gifted by J. Green, University of Sheffield and was used as a donor for transduction in the construction of $\operatorname{clp} X$ strains. Strains were grown in LB broth or on LB agar plates, supplemented with ampicillin $\left(100 \mu \mathrm{g} \mathrm{mL}^{-1}\right)$, chloramphenicol $\left(25 \mu \mathrm{g} \mathrm{mL}{ }^{-1}\right)$ or kanamycin $\left(50 \mu \mathrm{g} \mathrm{mL}^{-1}\right)$ or Isopropyl $\beta$-D-1-thiogalactopyranoside (IPTG) (concentration stated in figure legends) as appropriate. Prior to assaying protein secretion by SDS-PAGE or enzymatic secretion assay, fresh media was inoculated with cells from a liquid overnight culture and induced. Bacteria were grown with shaking at $180 \mathrm{rpm}, 37^{\circ} \mathrm{C}$.

\section{P1 phage transduction}

Phage transduction was carried out by the method outlined by Lennox [92]. Following strain construction, the eradication of phage from the strain was ensured by passaging on LB agar plates with $10 \mathrm{mM}$ sodium citrate. Absence of phage was then confirmed by Evans Blue-Uranine assay, as outlined by Tiruvadi Krishnan et al. [93].

\section{Recombinant DNA techniques}

Plasmids utilised for chromosomal manipulations or for cloning are listed in Additional file 1: Table S2. High fidelity and diagnostic polymerase chain reaction (PCR) was carried out with Phusion High Fidelity polymerase (New England Biosciences) and DreamTaq DNA Polymerase (Thermo Scientific) respectively. Templates and custom primers (Sigma-Aldrich) are listed in Additional file 1: Table S3. Chromosomal modifications were carried out, as described by Datsenko and Wanner [94]. To enable sequential mutagenesis, pCP20 was utilised to excise FRT flanked antibiotic resistance cassettes. Modifications were PCR verified, as was the maintenance of other lesions on the chromosome, if the strain underwent sequential deletions.

A genetic secretion construct was designed, synthesised and then incorporated into the pJexpress-404 plasmid backbone by DNA 2.0. This plasmid is referred to as pJex-fliC47-empty (Additional file 1: Fig. S4a) and forms the base cloning vehicle here. All restriction digests and ligation reactions were performed with NEB restriction enzymes and T4 DNA ligase (New England Biosciences). Following ligation, reaction mixes were transformed into NEB 5-alpha (New England Biosciences), as described in the supplier's instructions. The synthetic gene for Fusarium solani cutinase (accession number: K02640), was codon optimised and synthesised by GeneArt ${ }^{\circledR}$ Strings DNA Fragments (Life Technologies). hGH and TrxA gene fragments were obtained from FUJIFILM Diosynth Biotechnologies.

\section{SDS-PAGE and western immunoblots}

Following cell growth for secretion, 1 OD unit of culture samples were centrifuged for $15 \mathrm{~min}(16,000 \mathrm{~g})$ to ensure separation of cells and supernatant. Supernatant fractions were prepared by precipitation in $10 \% \mathrm{v} / \mathrm{v}$ trichloroacetic acid and washing in acetone $[57,95]$. Both supernatant precipitate and cell pellets were suspended in $2 \times$ SDS buffer $(10 \mathrm{~mL}$ glycerol, $1 \mathrm{~g}$ SDS, $0.1 \mathrm{~g}$ bromophenol blue, $200 \mathrm{mM}$ DTT, to a volume of $50 \mathrm{~mL}$ in $100 \mathrm{mM}$ Tris- $\mathrm{HCl}, \mathrm{pH}$ 6.8) to a final volume of $50 \mu \mathrm{L}$ and $200 \mu \mathrm{L}$ respectively. Both cell lysate and supernatant samples 
underwent SDS-polyacrylamide gel electrophoresis (SDS-PAGE). Gels were either stained with InstantBlue ${ }^{\mathrm{TM}}$ (Expedeon) or prepared for Western immunoblotting by electro-transfer onto nitrocellulose membrane (GE Healthcare Life Science) and blocked in 3\% w/v bovine serum albumin in TBS $\left(24 \mathrm{~g} \mathrm{~L}^{-1}\right.$ Tris base, $88 \mathrm{~g} \mathrm{~L}^{-1} \mathrm{NaCl}$ plus $0.1 \% \mathrm{v} / \mathrm{v}$ Tween). The following primary antibodies were diluted 1 in 1000 in TBS/Tween: H48 monospecific $\mathrm{H}$ rabbit antiserum (Statens Serum Institut), monoclonal ANTI-FLAG ${ }^{\circledR}$ M2 antibody produced in mouse (SigmaAldrich), E. coli GroEL rabbit IgG (Sigma-Aldrich). If required, following washing and re-blocking, anti-rabbit HRP (Cell Signalling Technology) was diluted 1 in 3000. All blocking and incubation steps were carried out for $1 \mathrm{~h}$. Immunoblots were visualised using Pierce ${ }^{\circledR}$ ECL Western Blotting Substrates (Thermo Scientific) and a Compact X4 X-ray Film Processor (Xograph) or $\mathrm{C}$-DiGit ${ }^{\circledR}$ Chemiluminescent Western Blot Scanner (LICOR Biosciences). Analysis by densitometry was carried out using ImageJ. For FlhA detection, the same protocol was followed except blocking was carried out in 5\% w/v skimmed milk in PBS $\left(8 \mathrm{~g} \mathrm{~L}^{-1} \mathrm{NaCl}, 0.2 \mathrm{~g} \mathrm{~L}^{-1} \mathrm{KCl}\right.$, $1.44 \mathrm{~g} \mathrm{~L}^{-1} \mathrm{Na}_{2} \mathrm{HPO}_{4}, 0.24 \mathrm{~g} \mathrm{~L}^{-1} \mathrm{KH}_{2} \mathrm{PO}_{4}$ ) with $0.05 \% \mathrm{v} / \mathrm{v}$ Triton X100. Polyclonal anti-FlhA antisera was diluted 1 in 1000 in PBS/Triton along with E. coli $\triangle f l h D C$ soluble cell lysate (to minimise non-specific binding) and following washing, membranes were incubated with a 1 in 5000 dilution of IRDye $800 \mathrm{CW}$ Donkey anti-rabbit secondary antibody (LI-COR Biosciences). Membranes were analysed using an Azure c500 (Azure Biosystems) imaging system and quantified with LI-COR Image Studio Lite (LI-COR Biosciences).

\section{Protein purification for preparation of standards}

To prepare purified monomers of truncated FliC, MC1000 $\Delta f l i C$ harbouring PTrc-FliC- $\Delta$ DE3 were scraped from semisoft agar plates $(1 \% \mathrm{w} / \mathrm{v}$ tryptone, $0.5 \% \mathrm{NaCl}$, $0.8 \% \mathrm{w} / \mathrm{v}$ bacteriological agar), following $24 \mathrm{~h}$ incubation at $37^{\circ} \mathrm{C}$. After resuspension in $50 \mathrm{mM}$ Tris- $\mathrm{HCl}, \mathrm{pH}$ 7.8 , cells were agitated vigorously in a laboratory blender (Waring Laboratory Science) for $3 \mathrm{~min}$, then centrifuged at $16,000 \mathrm{~g}$ for $5 \mathrm{~min}$ at $4{ }^{\circ} \mathrm{C}$. The supernatant was then centrifuged at $67,500 \mathrm{~g}$ for $15 \mathrm{~min}$ at $4{ }^{\circ} \mathrm{C}$. The pellet was resuspended in fresh buffer, and centrifugation repeated. In fresh buffer, the pellet underwent sonication for $20 \mathrm{~s}$, followed by heating to $50{ }^{\circ} \mathrm{C}$ for $10 \mathrm{~min}$ to cause monomerisation. Finally, centrifugation was repeated and supernatant collected.

Protein standards of $\mathrm{CH}_{2}$, TrxA and hGH were purified from the intracellular fraction of $E$. coli BL21 (DE3) after induction with $1 \mathrm{mM}$ IPTG. Protein was purified using the secretion construct incorporated Streptavadin II tag on a $1 \mathrm{~mL}$ StrepTrap ${ }^{\mathrm{TM}}$ HP column (GE Healthcare Life Science) according to the manufacturer's instructions. Following elution with $2.5 \mathrm{mM}$ desthiobiotin, $100 \mathrm{mM}$ Tris- $\mathrm{HCl}, 150 \mathrm{mM} \mathrm{NaCl}, 1 \mathrm{mM}$ EDTA, $\mathrm{pH}$ 8, protein underwent dialysis overnight to yield purified protein in $100 \mathrm{mM}$ Tris- $\mathrm{HCl}, \mathrm{pH} 8$ and quantified with a Pierce ${ }^{\text {TM }}$ BCA Protein Assay Kit (Thermo Scientific). Proteins standards were aliquoted and stored at $-20^{\circ} \mathrm{C}$.

\section{Cutinase based protein secretion assay}

An assay based on cleavage of 4-methylumbelliferyl butyrate (MUB) was developed to measure the activity of secreted cutinase. $10 \mathrm{~mL}$ cultures of cells expressing cutinase were induced with $0.05 \mathrm{mM}$ IPTG and grown to $\mathrm{OD}_{600}$ 1.0. $250 \mathrm{mM}$ MUB (prepared fresh daily) was dissolved in dimethylformamide with $1 \%$ Triton X-100. This mixture was then diluted in $50 \mathrm{mM}$ phosphate citrate (pH 5) buffer to a working concentration of $500 \mu \mathrm{M}$ MUB. $40 \mu \mathrm{L}$ supernatant was added to 96 well plate wells, the reaction was initiated with the addition of $160 \mu \mathrm{L}$ MUB and incubated at $30^{\circ} \mathrm{C}$ for $30 \mathrm{~min}$. Following incubation, fluorescence was measured, either by imaging 96 well plates under UV light (G:BOX, Syngene), or using a Tecan Infinite 200 Pro plate reader-excitation $302 \mathrm{~nm}$, emission $446 \mathrm{~nm}$ (Tecan Group Ltd.).

\section{Additional file}

Additional file 1: Table S1. Escherichia coli strains used or generated in this study. Table S2. Plasmids used or generated in this study. Table S3. Polymerase chain reaction primers used in the study. Fig. S1. Annotation of the genetic region upstream of the flhD operon in E. coli MC1000. Fig. S2. Comparison of growth of the HAP-less and cap-less strains. Growth curve data for the aforementioned strains. Fig. S3. Functional flagellar despite the absence of the FliC D3 domain. SDS-PAGE of secreted protein and motility assay. Fig. S4. The effect of the deletion of clpX from E. coli MC1000. Comparison of the strains by: abundance of secreted flagellin, motility assay and phenotype. Fig. S5. Plasmid maps of (a) pJex-flic47empty and (b) pJex-flic47-cutinase, along with (c) the prototype genetic synthetic modular secretion construct of pJex-flic47-cutinase. Fig. S6. Comparison of growth of truncated FT3SS secretion strains. Growth curves for all relevant strains. Fig. S7. The FliC secretion signal is required to enable secretion. Immunoblots of secreted and intracellular cutinase. Fig. S8. Comparison of the "late' FliC and 'early' secretion signals. Schematic of secretion constructs and immunoblots of secreted and intracellular cutinase. Fig. S9. Secretion of a range of substrates through the optimised secretion strain. Immunoblots of secreted protein alongside a protein standard.

\section{Abbreviations \\ FT3SS: flagellar type III secretion system; T2SS: type II secretion system; IB: industrial biotechnology; MUB: 4-methylumbelliferyl butyrate; SC: secretion construct; TrxA: thioredoxin; hGH: human growth hormone.}

\section{Authors' contributions}

CAG generated the majority of strains and plasmids, performed and optimised secretion experiments, including SDS-PAGE and immunoblotting, developed the cutinase secretion assay, designed experiments and interpreted data, 
alongside NK, EC, MH and OJB. CAG and GS lead the project design and manuscript writing. $C L$ provided the $h G H$ and TrxA coding sequence and insight into industrial protein production processes. PCW, GS, MH and CAG contributed to the study design and inception. All authors read and approved the final manuscript.

\begin{abstract}
Author details
${ }^{1}$ Integrated BioSciences, School of Clinical Dentistry, University of Sheffield, Sheffield S10 2TA, UK. ${ }^{2}$ School of Engineering, The Faculty of Science, Agriculture and Engineering, Newcastle University, Newcastle NE1 7RU, UK. ${ }^{3}$ Department of Pathology, University of Cambridge, Cambridge CB2 1QP, UK. ${ }^{4}$ FUJIFILM Diosynth Biotechnologies, Belasis Avenue, Stockton-on-Tees, Billingham TS23 1LH, UK. ${ }^{5}$ Sustainable Process Technologies, Chemical and Environmental Engineering, University of Nottingham, Nottingham NG7 2RD, UK.
\end{abstract}

\section{Acknowledgements}

We would like to thank J. Green and J. Pandhal for strains and the $\mathrm{CH}_{2}$ gene respectively. We thank FUJIFILM Diosynth Biotechnolgies for provision of the coding sequence of human Growth Hormone ( $\mathrm{hGH}$ ) and Thioredoxin (TrxA).

\section{Competing interests}

The authors declare that they have no competing interests.

\section{Availability of data and materials}

All data generated or analysed during this study are included in this published article and its additional files.

\section{Consent for publication}

Not applicable.

\section{Ethics approval and consent to participate}

Not applicable.

\section{Funding}

CAG was funded by a University of Sheffield Ph.D. scholarship, NK by a Ph.D. scholarship from the Government of India, and EC by a BBSRC CBMNet Business Innovation voucher to GS and CL. MH was funded by BBSRC Grant to GS and PCW (BB/J016322/1). OJB was funded by a John Lucas Walker studentship awarded by the Department of Pathology, University of Cambridge, and GMF was funded by BBSRC Project Grant BB/M007197/1.

\section{Publisher's Note}

Springer Nature remains neutral with regard to jurisdictional claims in published maps and institutional affiliations.

Received: 10 September 2018 Accepted: 8 January 2019

Published online: 18 January 2019

\section{References}

1. Ferrer-Miralles N, Villaverde A. Bacterial cell factories for recombinant protein production; expanding the catalogue. Microb Cell Fact. 2013;12:113. https://doi.org/10.1186/1475-2859-12-113.

2. Baeshen MN, Al-Hejin AM, Bora RS, Ahmed MMM, Ramadan HAl, Saini KS, et al. Production of Biopharmaceuticals in E. coli: current scenario and future perspectives. J Microbiol Biotechnol. 2015;25:953-62. https://doi. org/10.4014/jmb.1412.12079.

3. Hellwig S, Drossard J, Twyman RM, Fischer R. Plant cell cultures for the production of recombinant proteins. Nat Biotechnol. 2004;22:1415-22. https://doi.org/10.1038/nbt1027.

4. Walsh G. Biopharmaceutical benchmarks 2014. Nat Biotechnol. 2014;32:992-1000. https://doi.org/10.1038/nbt.3040.

5. Freudl R. Signal peptides for recombinant protein secretion in bacterial expression systems. Microb Cell Fact. 2018;17:52. https://doi.org/10.1186/ s12934-018-0901-3.

6. van der Wal FJ, Koningstein G, ten Hagen CM, Oudega B, Luirink J. Optimization of bacteriocin release protein (BRP)-mediated protein release by Escherichia coli: random mutagenesis of the pCloDF13-derived BRP gene to uncouple lethality and quasi-lysis from protein release. Appl Environ Microbiol. 1998;64:392-8.

7. Schädlich L, Senger T, Kirschning CJ, Müller M, Gissmann L. Refining HPV $16 \mathrm{~L} 1$ purification from $E$. coli: reducing endotoxin contaminations and their impact on immunogenicity. Vaccine. 2009;27:1511-22. https://doi. org/10.1016/j.vaccine.2009.01.014

8. Wingfield PT. Overview of the purification of recombinant proteins. Curr Protoc protein Sci. 2015;80:1-35. https://doi.org/10.1002/0471140864 .ps0601s80.

9. Choi JH, Lee SY. Secretory and extracellular production of recombinant proteins using Escherichia coli. Appl Microbiol Biotechnol. 2004;64:62535. https://doi.org/10.1007/s00253-004-1559-9.

10. Mergulhão FJM, Summers DK, Monteiro GA. Recombinant protein secretion in Escherichia coli. Biotechnol Adv. 2005;23:177-202. https://doi. org/10.1016/j.biotechadv.2004.11.003.

11. Georgiou G, Segatori L. Preparative expression of secreted proteins in bacteria: status report and future prospects. Curr Opin Biotechnol. 2005;16:538-45. https://doi.org/10.1016/j.copbio.2005.07.008.

12. Ni Y, Chen R. Extracellular recombinant protein production from Escherichia coli. Biotechnol Lett. 2009;31:1661-70. https://doi.org/10.1007/s1052 9-009-0077-3.

13. Browning DF, Richards KL, Peswani AR, Roobol J, Busby SJW, Robinson C. Escherichia coli "TatExpress" strains super-secrete human growth hormone into the bacterial periplasm by the Tat pathway. Biotechnol Bioeng. 2017;114:2828-36. https://doi.org/10.1002/bit.26434.

14. Matos CFRO, Branston SD, Albiniak A, Dhanoya A, Freedman RB, Keshavarz-Moore E, et al. High-yield export of a native heterologous protein to the periplasm by the tat translocation pathway in Escherichia coli. Biotechnol Bioeng. 2012;109:2533-42. https://doi.org/10.1002/bit.24535.

15. Müller JM, Wetzel D, Flaschel E, Friehs K, Risse JM. Constitutive production and efficient secretion of soluble full-length streptavidin by an Escherichia coli'leaky mutant'. J Biotechnol. 2016;221:91-100. https://doi. org/10.1016/J.JBIOTEC.2016.01.032.

16. Wang $P, M a$ J, Zhang $Y$, Zhang M, Wu M, Dai Z, et al. Efficient secretory overexpression of endoinulinase in Escherichia coli and the production of inulooligosaccharides. Appl Biochem Biotechnol. 2016;179:880-94. https ://doi.org/10.1007/s12010-016-2037-4.

17. Pechsrichuang P, Songsiriritthigul C, Haltrich D, Roytrakul S, Namvijtr $P$, Bonaparte $\mathrm{N}$, et al. OmpA signal peptide leads to heterogenous secretion of $B$. subtilis chitosanase enzyme from E. coli expression system. Springerplus. 2016;5:1200. https://doi.org/10.1186/s40064-016-2893-y.

18. Ujiie A, Nakano H, Iwasaki Y. Extracellular production of Pseudozyma (Candida) antarctica lipase $B$ with genuine primary sequence in recombinant Escherichia coli. J Biosci Bioeng. 2016;121:303-9. https://doi. org/10.1016/J.JBIOSC.2015.07.001.

19. Olmos-Soto J, Contreras-Flores R. Genetic system constructed to overproduce and secrete proinsulin in Bacillus subtilis. Appl Microbiol Biotechnol. 2003;62:369-73. https://doi.org/10.1007/s00253-003-1289-4.

20. Berger E, Crampton MC, Nxumalo NP, Louw ME. Extracellular secretion of a recombinant therapeutic peptide by Bacillus halodurans utilizing a modified flagellin type III secretion system. Microb Cell Fact. 2011;10:62. https://doi.org/10.1186/1475-2859-10-62.

21. Ryu J, Lee U, Park J, Yoo D-H, Ahn JH. A Vector system for ABC transportermediated secretion and purification of recombinant proteins in Pseudomonas species. Appl Environ Microbiol. 2015;81:1744-53. https://doi. org/10.1128/AEM.03514-14.

22. Werten MWT, van den Bosch TJ, Wind RD, Mooibroek H, de Wolf FA. High-yield secretion of recombinant gelatins by Pichia pastoris. Yeast. 1999;15:1087-96. https://doi.org/10.1002/(SICI)1097-0061(19990 8) 15:11\%3c1087:AID-YEA436\%3e3.0.CO;2-F.

23. Blight MA, Holland IB. Heterologous protein secretion and the versatile Escherichia coli haemolysin translocator. Trends Biotechnol. 1994;12:450-5.

24. Fernandez LA, de Lorenzo V. Formation of disulphide bonds during secretion of proteins through the periplasmic-independent type I pathway. Mol Microbiol. 2001;40:332-46. https://doi.org/10.104 6/j.1365-2958.2001.02410.x

25. Chung CW, You J, Kim K, Moon Y, Kim H, Ahn JH. Export of recombinant proteins in Escherichia coli using $A B C$ transporter with an attached lipase 
ABC transporter recognition domain (LARD). Microb Cell Fact. 2009;8:11. https://doi.org/10.1186/1475-2859-8-11.

26. Chervaux C, Sauvonnet N, Le Clainche A, Kenny B, Hung AL, BroomeSmith JK, et al. Secretion of active beta-lactamase to the medium mediated by the Escherichia coli haemolysin transport pathway. Mol Gen Genet. 1995;249:237-45.

27. Schwarz CKW, Landsberg CD, Lenders MHH, Smits SHJ, Schmitt L. Using an E. coli type 1 secretion system to secrete the mammalian, intracellular protein IFABP in its active form. J Biotechnol. 2012;159:155-61. https:// doi.org/10.1016/j.jbiotec.2012.02.005.

28. Bakkes PJ, Jenewein S, Smits SHJ, Holland IB, Schmitt L. The rate of folding dictates substrate secretion by the Escherichia coli hemolysin type 1 secretion system. J Biol Chem. 2010;285:40573-80. https://doi. org/10.1074/jbc.M110.173658.

29. Anton L, Majander K, Savilahti H, Laakkonen L, Westerlund-Wikstrom B. Two distinct regions in the model protein Peb1 are critical for its heterologous transport out of Escherichia coli. Microb Cell Fact. 2010;9:97. https ://doi.org/10.1186/1475-2859-9-97.

30. Majander K, Anton L, Antikainen J, Lång H, Brummer M, Korhonen TK, et al. Extracellular secretion of polypeptides using a modified Escherichia coli flagellar secretion apparatus. Nat Biotechnol. 2005;23:475-81. https:// doi.org/10.1038/nbt1077.

31. Narayanan N, Khan M, Chou CP. Enhancing functional expression of heterologous lipase B in Escherichia coli by extracellular secretion. J Ind Microbiol Biotechnol. 2010;37:349-61. https://doi.org/10.1007/s1029 5-009-0680-2

32. Heel T, Vogel GF, Lammirato A, Schneider R, Auer B. FlgM as a secretion moiety for the development of an inducible type III secretion system. PLoS ONE. 2013;8:e59034. https://doi.org/10.1371/journal.pone.0059034.

33. Singer HM, Erhardt M, Hughes KT. Comparative analysis of the secretion capability of early and late flagellar type III secretion substrates. $\mathrm{Mol}$ Microbiol. 2014;93:505-20. https://doi.org/10.1111/mmi.12675.

34. Dobó J, Varga J, Sajó R, Végh BM, Gál P, Závodszky P, et al. Application of a short, disordered $\mathrm{N}$-terminal flagellin segment, a fully functional flagellar type III export signal, to expression of secreted proteins. Appl Environ Microbiol. 2010;76:891-9. https://doi.org/10.1128/AEM.00858-09.

35. Végh BM, Gál P, Dobó J, Závodszky P, Vonderviszt F. Localization of the flagellum-specific secretion signal in Salmonella flagellin. Biochem Biophys Res Commun. 2006;345:93-8.

36. Singer HM, Erhardt M, Steiner AM, Zhang M-M, Yoshikami D, Bulaj G, et al. Selective purification of recombinant neuroactive peptides using the flagellar type III secretion system. MBio. 2012;3:e00115-212. https://doi. org/10.1128/mBio.00115-12.

37. Azam A, Li C, Metcalf KJ, Tullman-Ercek D. Type III secretion as a generalizable strategy for the production of full-length biopolymer-forming proteins. Biotechnol Bioeng. 2016;113:2313-20. https://doi.org/10.1002/ bit.25656.

38. Widmaier DM, Tullman-Ercek D, Mirsky EA, Hill R, Govindarajan S, Minshull J, et al. Engineering the Salmonella type III secretion system to export spider silk monomers. Mol Syst Biol. 2009;5:309. https://doi.org/10.1038/ msb.2009.62.

39. Metcalf KJ, Bevington JL, Rosales SL, Burdette LA, Valdivia E, TullmanErcek D. Proteins adopt functionally active conformations after type III secretion. Microb Cell Fact. 2016;15:213. https://doi.org/10.1186/s1293 4-016-0606-4.

40. Macnab RM. How bacteria assemble flagella. Annu Rev Microbiol. 2003;57:77-100. https://doi.org/10.1146/annurev.micro.57.030502.09083 2.

41. Chevance FFV, Hughes KT. Coordinating assembly of a bacterial macromolecular machine. Nat Rev Microbiol. 2008;6:455-65. https://doi. org/10.1038/nrmicro1887.

42. Lino T. Assembly of salmonella flagellin in vitro and in vivo. J Supramol Struct. 1974;2:372-84. https://doi.org/10.1002/jss.400020226.

43. Emerson SU, Tokuyasu K, Simon MI. Bacterial flagella: polarity of elongation. Science. 1970;169:190-2. https://doi.org/10.1126/SCIEN CE.169.3941.190.

44. Yonekura K, Maki-Yonekura S, Namba K. Complete atomic model of the bacterial flagellar filament by electron cryomicroscopy. Nature. 2003;424:643-50. https://doi.org/10.1038/nature01830.
45. Chilcott GS, Hughes KT. Coupling of flagellar gene expression to flagellar assembly in Salmonella enterica Serovar Typhimurium and Escherichia coli. Microbiol Mol Biol Rev. 2000;64:694-708. https://doi.org/10.1128/ MMBR.64.4.694-708.2000.

46. Kutsukake K. Excretion of the anti-sigma factor through a flagellar substructure couples flagellar gene expression with flagellar assembly in Salmonella typhimurium. Mol Gen Genet MGG. 1994;243:605-12. https:// doi.org/10.1007/BF00279569.

47. Claret $L$, Hughes $C$. Interaction of the atypical prokaryotic transcription activator FlhD2C2 with early promoters of the flagellar gene hierarchy. J Mol Biol. 2002;321:185-99. https://doi.org/10.1016/S0022-2836(02)00600 -9 .

48. Hughes KT, Gillen KL, Semon MJ, Karlinsey JE. Sensing structural intermediates in bacterial flagellar assembly by export of a negative regulator. Science. 1993;262:1277-80.

49. Ohnishi K, Ohto Y, Aizawa S, Macnab RM, lino T. FlgD is a scaffolding protein needed for flagellar hook assembly in Salmonella typhimurium. J Bacteriol. 1994:176:2272-81.

50. Barembruch C, Hengge R. Cellular levels and activity of the flagellar sigma factor FliA of Escherichia coli are controlled by FlgM-modulated proteolysis. Mol Microbiol. 2007;65:76-89. https://doi.org/10.111 1/j.1365-2958.2007.05770.x.

51. Fahrner KA, Berg HC. Mutations that stimulate fhDDC expression in Escherichia coli K-12. J Bacteriol. 2015;197:3087-96. https://doi.org/10.1128/ JB.00455-15.

52. Soutourina $\mathrm{OA}$, Bertin PN. Regulation cascade of flagellar expression in Gram-negative bacteria. FEMS Microbiol Rev. 2003;27:505.

53. Paradis G, Chevance FFV, Liou W, Renault TT, Hughes KT, Rainville S, et al. Variability in bacterial flagella re-growth patterns after breakage. Sci Rep. 2017;7:1282. https://doi.org/10.1038/s41598-017-01302-5.

54. Turner L, Stern AS, Berg HC. Growth of flagellar filaments of Escherichia coli is independent of filament length. J Bacteriol. 2012;194:2437-42. https://doi.org/10.1128/JB.06735-11.

55. Yonekura K, Maki-Yonekura S, Namba K. Growth mechanism of the bacterial flagellar filament. Res Microbiol. 2002;153:191-7.

56. Homma M, Fujita $H$, Yamaguchi S, lino T. Excretion of unassembled flagellin by Salmonella typhimurium mutants deficient in hook-associated proteins. J Bacteriol. 1984;159:1056-9.

57. Stafford GP, Evans LDB, Krumscheid R, Dhillon P, Fraser GM, Hughes C. Sorting of early and late flagellar subunits after docking at the membrane ATPase of the type III export pathway. J Mol Biol. 2007;374:877-82. https ://doi.org/10.1016/J.JMB.2007.09.080.

58. Shin S, Park C. Modulation of flagellar expression in Escherichia coli by acetyl phosphate and the osmoregulator OmpR. J Bacteriol. 1995;177:4696-702

59. Lehnen D, Blumer C, Polen T, Wackwitz B, Wendisch VF, Unden G. LrhA as a new transcriptional key regulator of flagella, motility and chemotaxis genes in Escherichia coli. Mol Microbiol. 2002;45:521-32. https://doi.org/1 0.1046/j.1365-2958.2002.03032.x.

60. Barker CS, Prüss BM, Matsumura P. Increased motility of Escherichia coli by insertion sequence element integration into the regulatory region of the flhD operon. J Bacteriol. 2004;186:7529-37.

61. Yamamoto S, Kutsukake K. FliT acts as an anti-FlhD2C2 factor in the transcriptional control of the flagellar regulon in Salmonella enterica serovar typhimurium. J Bacteriol. 2006;188:6703-8. https://doi.org/10.1128/ JB.00799-06.

62. Sato Y, Takaya A, Mouslim C, Hughes KT, Yamamoto T. FliT selectively enhances proteolysis of FlhC subunit in $\mathrm{FlhD}_{4} \mathrm{C}_{2}$ complex by an ATPdependent protease, ClpXP. J Biol Chem. 2014;289:33001-11. https://doi. org/10.1074/jbc.M114.593749.

63. Hirano T, Minamino T, Namba K, Macnab RM. Substrate specificity classes and the recognition signal for Salmonella type III flagellar export. J Bacteriol. 2003;185:2485-92.

64. Ortega J, Singh SK, Ishikawa T, Maurizi MR, Steven AC. Visualization of substrate binding and translocation by the ATP-dependent protease, ClpXP. Mol Cell. 2000;6:1515-21. https://doi.org/10.1016/S1097-2765(00)00148 -9 .

65. Tomoyasu T, Ohkishi T, Ukyo Y, Tokumitsu A, Takaya A, Suzuki M, et al. The ClpXP ATP-dependent protease regulates flagellum synthesis in Salmonella enterica Serovar Typhimurium. J Bacteriol. 2002;184:645-53. https:// doi.org/10.1128/JB.184.3.645-653.2002. 
66. Kitagawa R, Takaya A, Yamamoto T. Dual regulatory pathways of flagellar gene expression by ClpXP protease in enterohaemorrhagic Escherichia coli. Microbiology. 2011;157(Pt 11):3094-103. https://doi.org/10.1099/ mic.0.051151-0.

67. Guo S, Alshamy I, Hughes KT, Chevance FFV. Analysis of factors that affect FlgM-dependent type III secretion for protein purification with Salmonella enterica serovar Typhimurium. J Bacteriol. 2014;196:2333-47. https:// doi.org/10.1128/JB.01572-14.

68. Lemke JJ, Durfee T, Gourse RL. DksA and ppGpp directly regulate transcription of the Escherichia coli flagellar cascade. Mol Microbiol. 2009;74:1368-79. https://doi.org/10.1111/j.1365-2958.2009.06939.x.

69. Aberg A, Fernández-Vázquez J, Cabrer-Panes JD, Sánchez A, Balsalobre C. Similar and divergent effects of ppGpp and DksA deficiencies on transcription in Escherichia coli. J Bacteriol. 2009;191:3226-36. https://doi. org/10.1128/JB.01410-08.

70. Vonderviszt F, Ishima R, Akasaka K, Aizawa S-I. Terminal disorder: a common structural feature of the axial proteins of bacterial flagellum? J Mol Biol. 1992;226:575-9. https://doi.org/10.1016/0022-2836(92)90616-R.

71. Ohnishi K, Kutsukake K, Suzuki H, lino T. Gene fliA encodes an alternative sigma factor specific for flagellar operons in Salmonella typhimurium. Mol Gen Genet. 1990;221:139-47.

72. Aldridge P, Gnerer J, Karlinsey JE, Hughes KT. Transcriptional and translational control of the Salmonella fliC gene. J Bacteriol. 2006;188:4487-96. https://doi.org/10.1128/JB.00094-06.

73. Abergel C, Martinez C, Fontecilla-Camps J, Cambillau C, de Geus P, Lauwereys M. Crystallization and preliminary X-ray study of a recombinant cutinase from Fusarium solani pisi. J Mol Biol. 1990;215:215-6. https://doi. org/10.1016/S0022-2836(05)80339-0.

74. Liu Z, Gosser Y, Baker PJ, Ravee Y, Lu Z, Alemu G, et al. Structural and functional studies of Aspergillus oryzae cutinase: enhanced thermostability and hydrolytic activity of synthetic ester and polyester degradation. J Am Chem Soc. 2009;131:15711-6. https://doi.org/10.1021/ja9046697.

75. Carvalho CML, Aires-Barros MR, Cabral JMS. Cutinase structure, function and biocatalytic applications. EJB Electron J Biotechnol. 1998;1:717-845.

76. Wei R, Zimmermann W. Microbial enzymes for the recycling of recalcitrant petroleum-based plastics: how far are we? Microb Biotechnol. 2017;10:1308-22. https://doi.org/10.1111/1751-7915.12710.

77. Ferrario V, Pellis A, Cespugli M, Guebitz G, Gardossi L, Ferrario V, et al. Nature inspired solutions for polymers: will cutinase enzymes make polyesters and polyamides greener? Catalysts. 2016;6:205. https://doi. org/10.3390/catal6120205.

78. Yang S, Xu H, Yan Q, Liu Y, Zhou P, Jiang Z. A low molecular mass cutinase of Thielavia terrestris efficiently hydrolyzes poly(esters). J Ind Microbiol Biotechnol. 2013;40:217-26. https://doi.org/10.1007/s10295-012-1222-x.

79. Aldridge P, Karlinsey J, Hughes KT. The type III secretion chaperone FlgN regulates flagellar assembly via a negative feedback loop containing its chaperone substrates FlgK and FlgL. Mol Microbiol. 2003;49:1333-45. https://doi.org/10.1046/j.1365-2958.2003.03637.x.

80. Karlinsey JE, Lonner J, Brown KL, Hughes KT. Translation/secretion coupling by type III secretion systems. Cell. 2000;102:487-97.
81. Fraser GM, Bennett JCQ, Hughes C. Substrate-specific binding of hookassociated proteins by FlgN and FliT, putative chaperones for flagellum assembly. Mol Microbiol. 1999;32:569-80. https://doi.org/10.104 6/j.1365-2958.1999.01372.x.

82. Blair DF, Berg HC. The MotA protein of E. coli is a proton-conducting component of the flagellar motor. Cell. 1990;60:439-49. https://doi. org/10.1016/0092-8674(90)90595-6.

83. Zhou J, Sharp LL, Tang HL, Lloyd SA, Billings S, Braun TF, et al. Function of protonatable residues in the flagellar motor of Escherichia coli: a critical role for Asp 32 of MotB. J Bacteriol. 1998;180:2729-35.

84. Schwarz F, Huang W, Li C, Schulz BL, Lizak C, Palumbo A, et al. A combined method for producing homogeneous glycoproteins with eukaryotic N-glycosylation. Nat Chem Biol. 2010;6:264-6. https://doi.org/10.1038/ nchembio.314.

85. Pandhal J, OW SY, Noirel J, Wright PC. Improving N-glycosylation efficiency in Escherichia coli using shotgun proteomics, metabolic network analysis, and selective reaction monitoring. Biotechnol Bioeng. 2011;108:902-12. https://doi.org/10.1002/bit.23011.

86. Hosking ER, Vogt C, Bakker EP, Manson MD. The Escherichia coli MotAB proton channel unplugged. J Mol Biol. 2006;364:921-37.

87. Minamino T, Morimoto YV, Hara N, Aldridge PD, Namba K. The bacterial flagellar type III export gate complex is a dual fuel engine that can use both $\mathrm{H}+$ and $\mathrm{Na}+$ for flagellar protein export. PLoS Pathog. 2016;12:e1005495. https://doi.org/10.1371/journal.ppat.1005495.

88. Galeva A, Moroz N, Yoon Y-H, Hughes KT, Samatey FA, Kostyukova AS. Bacterial flagellin-specific chaperone FliS interacts with anti-sigma factor FlgM. J Bacteriol. 2014;196:1215-21. https://doi.org/10.1128/JB.01278-13.

89. Yokoseki T, lino T, Kutsukake K. Negative regulation by fliD, fliS, and fliT of the export of the flagellum-specific anti-sigma factor, FlgM, in Salmonella typhimurium. J Bacteriol. 1996;178:899-901.

90. Belasco JG. All things must pass: contrasts and commonalities in eukaryotic and bacterial mRNA decay. Nat Rev Mol Cell Biol. 2010;11:467-78. https://doi.org/10.1038/nrm2917.

91. Fernández LA. Prokaryotic expression of antibodies and affibodies. Curr Opin Biotechnol. 2004;15:364-73.

92. Lennox ES. Transduction of linked genetic characters of the host by bacteriophage P1. Virology. 1995;1:190-206.

93. Tiruvadi Krishnan S, Moolman MC, van Laar T, Meyer AS, Dekker NH. Essential validation methods for E. coli strains created by chromosome engineering. J Biol Eng. 2015;9:11. https://doi.org/10.1186/s1303 6-015-0008-x.

94. Datsenko KA, Wanner BL. One-step inactivation of chromosomal genes in Escherichia coli K-12 using PCR products. Proc Natl Acad Sci USA. 2000;97:6640-5. https://doi.org/10.1073/pnas.120163297.

95. Thomas J, Stafford GP, Hughes C. Docking of cytosolic chaperonesubstrate complexes at the membrane ATPase during flagellar type III protein export. Proc Natl Acad Sci USA. 2004;101:3945-50. https://doi. org/10.1073/pnas.0307223101.

Ready to submit your research? Choose BMC and benefit from:

- fast, convenient online submission

- thorough peer review by experienced researchers in your field

- rapid publication on acceptance

- support for research data, including large and complex data types

- gold Open Access which fosters wider collaboration and increased citations

- maximum visibility for your research: over $100 \mathrm{M}$ website views per year

At BMC, research is always in progress.

Learn more biomedcentral.com/submissions 